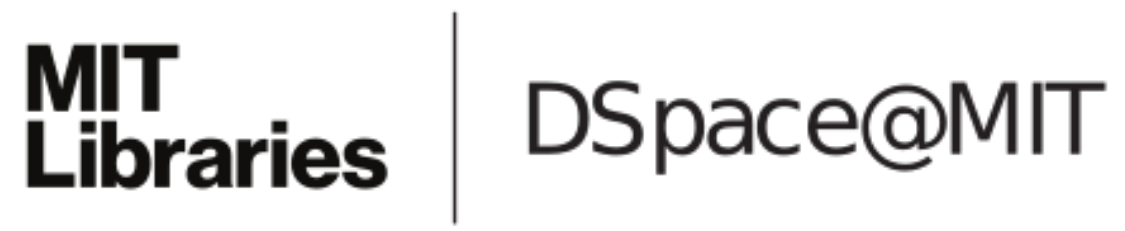

MIT Open Access Articles

The Assembly and Use of Continuous Flow Systems for Chemical Synthesis

The MIT Faculty has made this article openly available. Please share how this access benefits you. Your story matters.

Citation: Britton, Joshua, and Timothy F. Jamison. "The Assembly and Use of Continuous Flow Systems for Chemical Synthesis." Nature Protocols, vol. 12, no. 11, Oct. 2017, pp. 2423-46.

As Published: http://dx.doi.org/doi:10.1038/nprot.2017.102

Publisher: Nature Publishing Group

Persistent URL: http://hdl.handle.net/1721.1/114610

Version: Author's final manuscript: final author's manuscript post peer review, without publisher's formatting or copy editing

Terms of Use: Article is made available in accordance with the publisher's policy and may be subject to US copyright law. Please refer to the publisher's site for terms of use. 


\title{
The Assembly and Use of Continuous-Flow Systems for Chemical Synthesis
}

\author{
Dr. Joshua Britton and Prof. Dr. Timothy F. Jamison**
}

Department of Chemistry, Massachusetts Institute of Technology, 77 Massachusetts Avenue, Cambridge, MA 02139 (USA)

\begin{abstract}
The adoption and opportunities in continuous-flow chemical synthesis ("flow chemistry") have increased significantly over the past several years. Nevertheless, while several continuous-flow platforms are commercially available, 'in-lab' constructed systems provide researchers with a flexible, versatile, and cost-effective alternative. Herein, we describe how to assemble modular continuous-flow apparatus from readily available and affordable parts in as little as 30 minutes. Furthermore, our experiences in single- and multi-step continuous-flow synthesis have been documented to provide solutions to commonly encountered technical problems. Following this Protocol, a non-specialist can assemble a continuous-flow system from reactor coils, syringes, in-line liquid-liquid separators, drying columns, back pressure regulators, static mixers, and packed bed reactors.
\end{abstract}




\section{INTRODUCTION}

This century has observed an overwhelming advancement in the understanding and synthesis of organic compounds. In contrast, laboratory technology has remained much the same; reactions are still labor intensive and performed in round bottom flasks housing stir bars and reflux condensers. Although this style of chemistry (termed batch chemistry) is often suitable for chemical transformations, increasing research has demonstrated that continuous flow can provide a swathe of benefits. ${ }^{1-9}$ Translating reactions into continuous flow can provide a level of control and automation not possible in batch reactions. Improving the heat and mass transfer, ${ }^{10,11}$ micromixing, ${ }^{12}$ radiation penetration, ${ }^{13-16}$ and homogeneity ${ }^{6}$ of reactions has provided practical solutions to improve reaction efficiencies. Moreover, continuous flow allows the safe handling of hazardous species. Generating toxic compounds in situ for immediate consumption in sequential reactions avoids stockpiling risk-prone compounds. ${ }^{1,4,8}$ Harnessing increased reaction efficiencies, environmental sustainability, and improved safety metrics has lead to the adoption of continuous flow into both academia and industry. ${ }^{3,17-21}$

At its core, continuous-flow synthesis is achieved by pumping solutions of reactants through reactors in a continuous fashion (Fig. 1A). For lab-scale purposes, syringe, HPLC, or peristaltic pumps drive fluid through reactor coils, or microfluidic chips, with the residence time of the fluid dictated by the total flow rate and reactor volume. Although single reactor coils are commonly utilized, advancements of in-line technology have provided opportunities to explore more complex, multi-step transformations. ${ }^{6,22}$ In this context, in-line refers to a manipulation, or analysis, of the continuous-flow stream without the solution exiting the continuous-flow system. The ability to perform aqueous workups, drying, and other purification procedures has also advanced continuous-flow notably.

Multi-step continuous-flow systems have provided rapid syntheses of active pharmaceutical ingredients (APIs) and natural product intermediates as well as effective functional group transformations. ${ }^{3,9}$ What started as a niche discipline in academia around ten years ago has evolved into a rapidly diversifying and expanding research area. Furthermore, materials, ${ }^{23-26}$ biochemical $^{27-30}$ and biofuels ${ }^{31-34}$ processes have been translated into continuous-flow systems with success. In 2005, Lonza Ltd. stated that $\sim 50 \%$ of chemical processes could benefit from translation into continuousflow. ${ }^{35}$ In this respect, it is vital that all researchers wishing to contribute, and advance this area, have access to readily available and operationally simple continuous-flow equipment.

Although continuous-flow chemistry has a plethora of benefits, it has drawbacks and limitations as well. For example, handling solids in continuous-flow is difficult due to reactor clogging. Though advancements in reaction engineering and immobilized reagents have overcome this to a certain extent, further innovation is needed. The most challenging constraints for academics, however, remain the high costs and significant time investment needed to conduct continuous-flow research. ${ }^{13}$ First, pumping modules are by far the most expensive component of a continuousflow system (\$1000-20,000 USD). Second, purchasing commercially available reactors and equipment increases the cost of continuous-flow synthesis immeasurably. Furthermore, researchers are often reliant on long delivery periods for equipment. Although syringe pump costs are fixed, the other constraints can be overcome through the assembly of modular continuous-flow systems from commercially available and affordable components (Fig 1A). This not only reduces the time and cost associated with continuous-flow chemistry, but opens up continuous-flow chemistry to all. 
A. Continuous-Flow Equipment

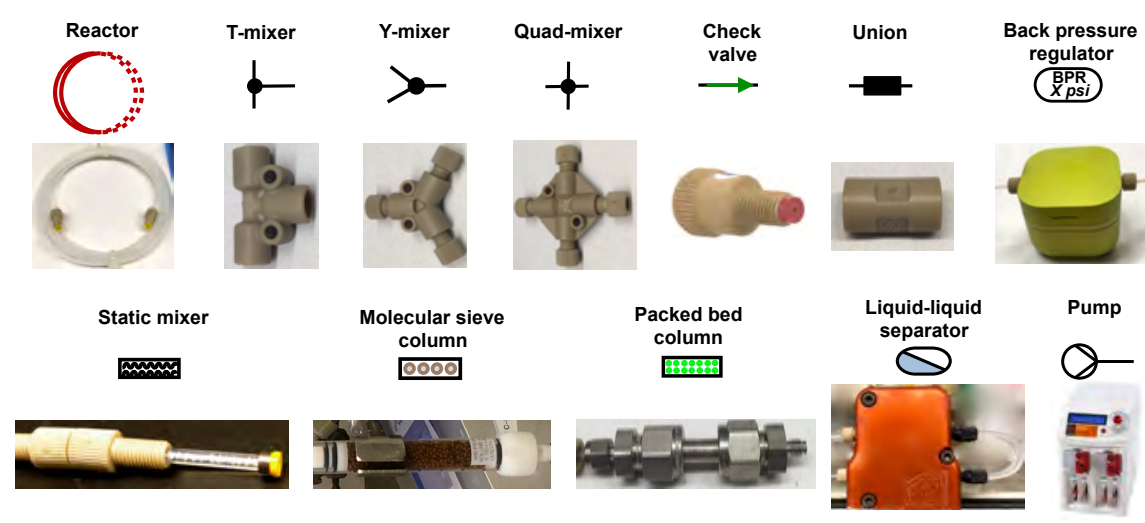

B. Examples of Continuous-Flow Synthesis
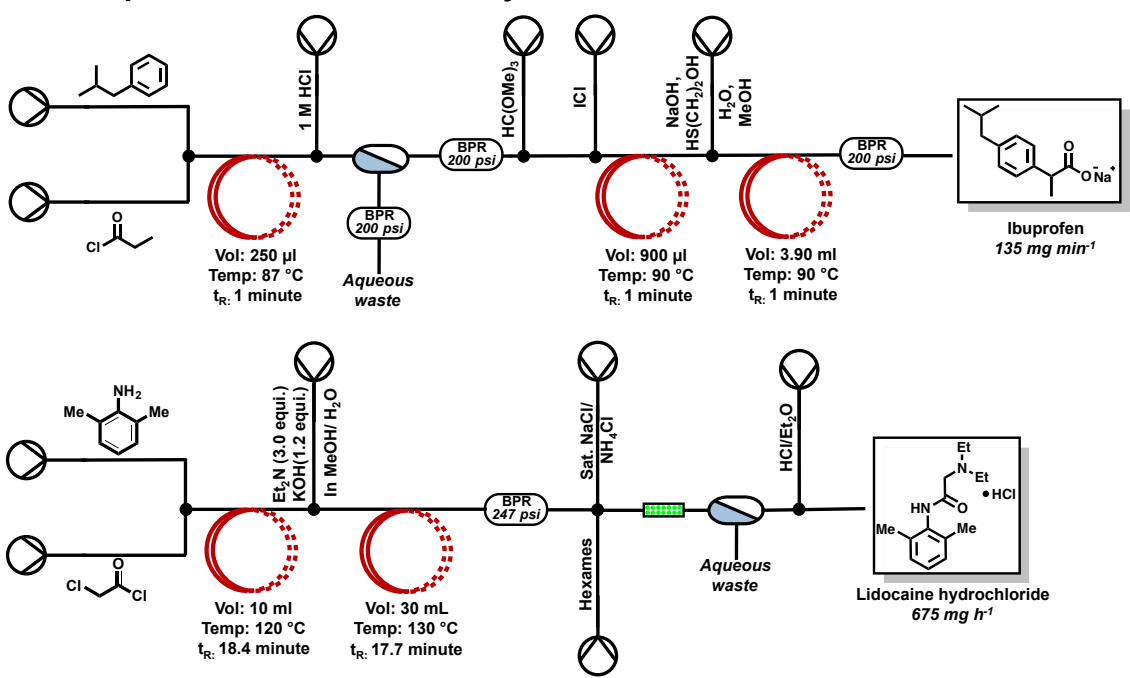

Figure 1| Continuous-flow equipment and its use in the multi-step continuous-flow synthesis of active pharmaceutical ingredients (A) Typical equipment used in the assembly of continuous-flow systems that is discussed in this protocol. (B) Multi-step continuous-flow syntheses of ibuprofen and lidocaine hydrochloride as published by our laboratory. ${ }^{36,37}$

\section{Development of the protocol}

Our laboratory maintains that modular continuous-flow equipment can be readily assembled from affordable and commercially available components, allowing researchers to explore continuous-flow synthesis without purchasing expensive equipment. In developing this concept, the synthesis of APIs and commodity chemicals such as ibuprofen, ${ }^{37}$ lidocaine hydrochloride, ${ }^{36}$ diphenhydramine hydrochloride, ${ }^{36,38}$ diazepam, ${ }^{36}$ fluoxetine hydrochloride, ${ }^{36}$ atropine,${ }^{39}$ rufinamide $^{40}$ and aliskiren ${ }^{41,42}$ have been achieved (Fig. 1B). Furthermore, fluorination using $\mathrm{SF}_{6},{ }^{43}$ biocatalysis, ${ }^{44}$ controlled polymer growth, ${ }^{45}$ and a range of synthetic transformations have been mediated on 'in-lab' constructed systems. $^{16,46-56}$

As with traditional organic synthesis, a range of accessories is required for continuous-flow synthesis. Typically, systems are operated with a back pressure regulator to ensure fluid homogeneity as it proceeds through the reactor; no back pressure can decrease fluid residence times due to lack of resistance (Fig. 1A). Operating under a back pressure also allows solvents to be heated above their atmospheric boiling points, affording opportunities for improved reaction kinetics. Analogous to stir bars in round bottom flasks, static mixers and packed bed reactors micromix solutions in a continuous manner (Fig. 1A). Packed bed reactors can also house immobilized reagents to utilize solid reagents in continuous flow. Moreover, in-line liquid-liquid separators housing a semi-permeable membrane can isolate immiscible fluids to purify intermediates. Finally, drying units containing molecular sieves can remove water from solutions before 
subsequent moisture sensitive transformations. Combining these modules into specific orders allows researchers to translate a large number of synthetic protocols into continuous-flow systems.

Our laboratory strives to ensure that continuous-flow apparatus is $(i)$ modular, so it can be easily removed and replaced to afford a variety of systems, (ii) simple and quick to assemble from readily available and cost effective parts, and (iii) easy to operate to allow both new, and experienced researchers to harness the benefits of continuous-flow chemistry. For example, the synthesis of lidocaine hydrochloride requires assembling multiple syringes, pumps, reactor coils, a back pressure regulator, and an in-line liquid-liquid separator (Fig. 1B). To then synthesize ibuprofen, users need only to rearrange the syringe pumps, add a new reactor coil, and then exchange a static mixer for a back pressure regulator. This whole process takes $\sim 30$ minutes and allows the synthesis of another API.

\section{Overview of the procedure}

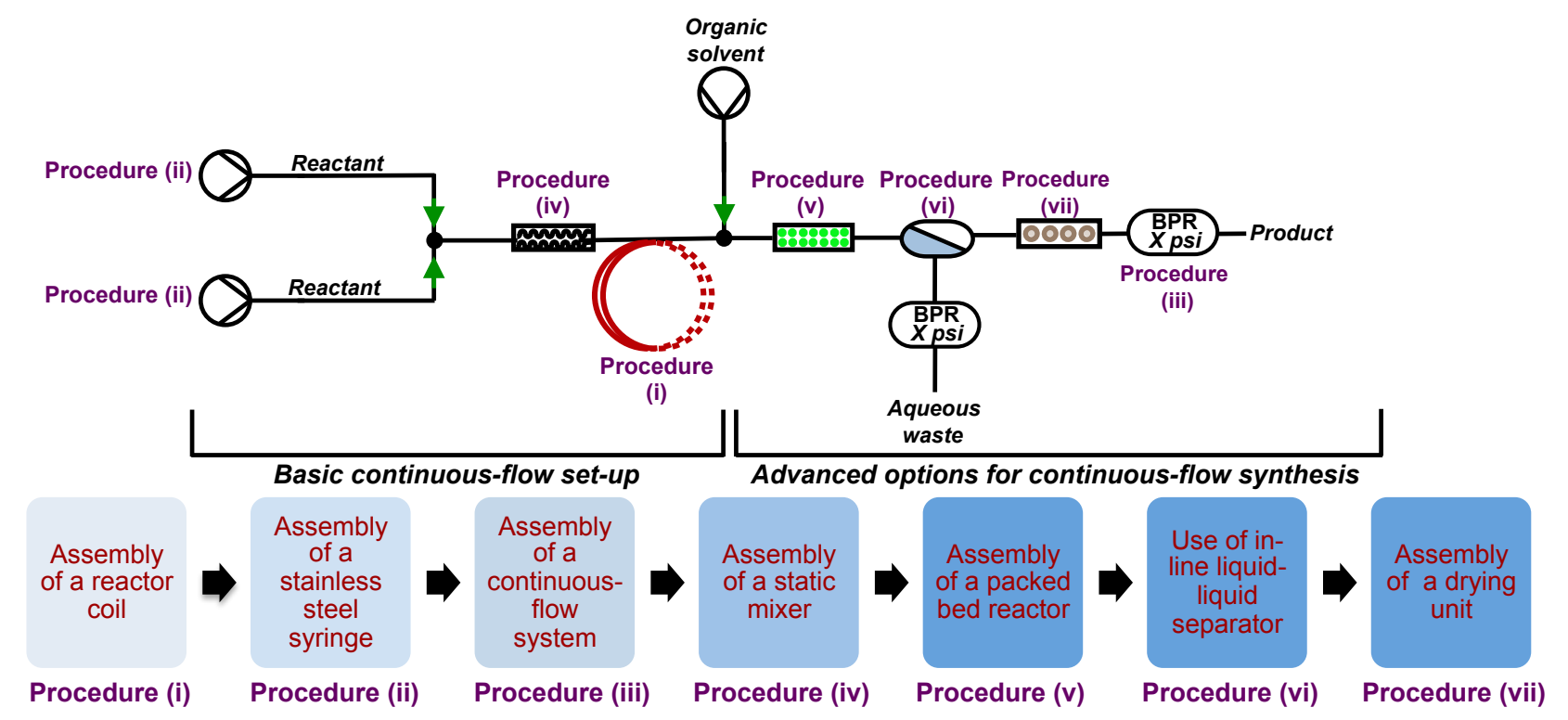

Figure 2| Outline of the equipment constructed in this protocol. First the assembly of a basic continuous-flow set up is detailed from procedure $i$-iii. Then, the assembly of advanced continuous-flow flow equipment is detailed from procedure $i v$-vii.

In this protocol, the assembly, use, and troubleshooting of modular continuous-flow systems are discussed. For reader convenience, the protocol has been split into two sections. The first describes the assembly of basic continuousflow equipment. The second describes the incorporation of advanced in-line technologies for more complex syntheses. For basic continuous-flow systems, the assembly of reactor coils from PFA tubing and the assembly of stainless steel syringes are discussed. Finally, the assembly of a continuous-flow system housing a back pressure regulator, two syringes, and a single reactor coil is demonstrated. For those new to continuous flow, this is the most basic set up. The skills learned in this section, however, can be applied to the assembly of more complex systems in future syntheses.

In the advanced section, the assembly, inclusion, and use of in-line technology will be described to allow more complex, multi-step continuous-flow transformations (Fig. 1B). First, the assembly of a static mixer and a packed bed reactor for increased mixing of solutions is discussed. Second, the use of a liquid-liquid separator for intermediate purification is detailed. Finally, how to assemble a drying unit housing molecular sieves is demonstrated. This protocol allows an undergraduate researcher to quickly assemble reactor coils, static mixers, stainless steel syringes, packed bed reactors, back pressure regulators, in-line liquid-liquid separators and drying units. Compiling this equipment into a simple modular continuous-flow system allows those new to the field to explore continuous-flow synthesis. 


\section{Controls}

Control reactions are essential for the optimization and understanding of continuous-flow systems. To effectively determine the yield, or conversion from a transformation occurring within the continuous-flow system, the reaction must be immediately quenched upon exit. There are several types of quenches including (i) chemical, (ii) thermal and (iii) isolation. Chemical quenches destroy one of the reagents to avoid further reactivity. Thermal quenches slow down the rate of reaction significantly so that the reaction mixture can be isolated or analyzed. Isolation quenches remove a reactant from the reaction mixture through a physical process such as evaporation, separation, or precipitation. To test whether your quench is suitable; first analyze the solution immediately after quenching it. Second, perform the same analysis on a quench after 30 mins. If a change in the yield results after $30 \mathrm{mins}$, the quench is ineffective. This consideration is especially important for those performing 'flash chemistry'. ${ }^{57,58}$ Here, synthetic transformations are mediated on very short time scales (seconds). Furthermore, it is important to separate reactive reagents into separate syringes to avoid reactivity prior to the continuous-flow system.

\section{MATERIALS}

\section{Equipment}

The equipment required for assembling modular continuous-flow systems is grouped below. Equipment marked with a

* is common to all procedures. This protocol uses 1/16" outer diameter PFA tubing as this gives the largest range of operational flexibility. If larger tubing is required, the complimentary ferrules, super flangeless nuts ${ }^{\mathrm{TM}}$ and low-pressure PEEK unions should be used. For example, if using 1/8" outer diameter PFA tubing, ensure the ferrules and super flangeless nuts ${ }^{\mathrm{TM}}$ are compatible with $1 / 8$ " diameter tubing.

\section{(i) Reactor coil}

Parts

DuPont ${ }^{\circledR} 0.02$ " inner diameter, 1/16" outer diameter PFA tubing (IDEX Health \& Science, \#1512L)*

Polymer tube cutters for 1/16" and 1/8" outer diameter tubing (IDEX Health \& Science, \#A-327)*

Ferrule sets for 1/16" outer diameter tubing (IDEX Health \& Science, \#P-250)*

Super flangeless nuts ${ }^{\mathrm{TM}}$ for $\leq 1 / 16$ " outer diameter tubing (IDEX Health \& Science, \#P-141)*

Low-pressure PEEK unions for 1/16" outer diameter tubing (IDEX Health \& Science, \#P-702)*

Tools

Extender tool for standard head nuts (IDEX Health \& Science, \#P-299)*

Cable ties (Staples, \#192314)

Sharp hooked tweezers (Aldrich, \#T4912)*

Pliers*

\section{(ii) Stainless steel syringe}

Parts

$8 \mathrm{~mL}$ stainless steel syringe kit with a 1/16" nut (Harvard apparatus, \#702267)

DuPont ${ }^{\circledR} 0.02$ " inner diameter, 1/16" outer diameter PFA tubing (IDEX Health \& Science, \#1512L)*

Ferrule sets for 1/16" outer diameter tubing (IDEX Health \& Science, \#P-250)*

Super flangeless nuts ${ }^{\mathrm{TM}}$ for $\leq 1 / 16$ " outer diameter tubing (IDEX Health \& Science, \#P-141)* 
Low-pressure PEEK unions for 1/16" outer diameter tubing (IDEX Health \& Science, \#P-702)*

Tools

Extender tool for standard head nuts (IDEX Health \& Science, \#P-299)*

Sharp hooked tweezers (Aldrich, \#T4912)*

Pliers*

$5 / 16$ " wrench

Bench vise

\section{(iii) Basic continuous-flow system}

Parts

DuPont ${ }^{\circledR} 0.02$ " inner diameter, 1/16" outer diameter PFA tubing (IDEX Health \& Science, \#1512L)*

Polymer tube cutters for 1/16" and 1/8" outer diameter tubing (IDEX Health \& Science, \#A-327)*

Ferrule sets for 1/16" outer diameter tubing (IDEX Health \& Science, \#P-250)*

Super flangeless nuts ${ }^{\mathrm{TM}}$ for $\leq 1 / 16$ " outer diameter tubing (IDEX Health \& Science, \#P-141)*

Low-pressure PEEK unions for 1/16" outer diameter tubing with a 0.02" thru (IDEX Health \& Science, \#P-702)*

Variable back pressure regulator kit containing a back pressure regulator and gas adapter (Zaiput Flow Technologies, \#BPR-10)

Standard 1/4-28 in-line check valves (IDEX Health \& Science, \#CV-3301)

Non-metallic 1/4-28 in-line check valves (IDEX Health \& Science, \#CV-3320)

PEEK T-junction mixer for 1/16" outer diameter tubing, 0.20 ” thru hole (IDEX Health \& Science, \#P-714)

$8 \mathrm{~mL}$ stainless steel syringe kit with a 1/16" nut (Harvard apparatus, \#702267)

Syringe pumps (Harvard PhD syringe pump, \#70-3005 or, Syrris Asia syringe pump, \#2200292)

Compressed gas tank and regulator

Krytox LVP grease (Aldrich, \#Z273546)

\section{Tools}

Polymer tube cutters for $1 / 16$ " and 1/8" outer diameter tubing (IDEX Health \& Science, \#A-327)*

Extender tool for standard head nuts (IDEX Health \& Science, \#P-299)*

Sharp hooked tweezers (Aldrich, \#T4912)*

Pliers*

Bench vise

\section{(iv) Static mixer}

Parts

Type HT Teflon static mixer, 10 mixing elements long (StaMixCo LLC, www.stamixco-usa.com) DuPont ${ }^{\circledR} 0.062$ " inner diameter, $1 / 8$ " outer diameter PFA tubing (IDEX Health \& Science, \#1521L)

Ferrule sets for $1 / 8$ " outer diameter tubing (IDEX Health \& Science, \#P-359X)

Super flangeless nuts ${ }^{\mathrm{TM}}$ for $1 / 8$ " outer diameter tubing (IDEX Health \& Science, \#P-331)

Low-pressure PEEK unions for 1/8” outer diameter tubing (IDEX Health \& Science, \#P-703) 
Polymer tube cutters for 1/16" and 1/8" outer diameter tubing (IDEX Health \& Science, \#A-327)*

Extender tool for standard head nuts (IDEX Health \& Science, \#P-299)*

Sharp hooked tweezers (Aldrich, \#T4912)*

Pliers*

\section{(iv) Packed bed reactor}

Parts

DuPont ${ }^{\circledR} 0.02$ " internal diameter, 1/16" outer diameter PFA tubing (IDEX Health \& Science, \#1512L)*

Ferrule sets for 1/16" outer diameter tubing (IDEX Health \& Science, \#P-250)*

Super flangeless nuts ${ }^{\mathrm{TM}}$ for $\leq 1 / 16$ " outer diameter tubing (IDEX Health \& Science, \#P-141)*

Low-pressure PEEK unions for 1/16" outer diameter tubing (IDEX Health \& Science, \#P-702)*

Stainless steel $10 \mu \mathrm{m}$ frits (IDEX Health \& Science, \#A-107)

Swagelok stainless zero volume reducing union 1/4" outer diameter (Swagelok, \#SS-400-6-1ZV)

Swagelok stainless ferrule set (one front and one back ferrule) (Swagelok, \#SS-100-SET)

Metal tube cutter (3-30 mm, 1/8" - 1 1/8”)

Seamless stainless steel tubing with a 0.180 " inner diameter, 1/4" external diameter, 0.035" wall thickness, max pressure of 4375 psi @ $72^{\circ} \mathrm{F}$ (Grainger, \#3ACH4).

$3 \mathrm{~mL}$ disposable syringe

Sand, 50-70 mesh particle size (Aldrich, \#274739)

Tools

Extender tool for standard head nuts (IDEX Health \& Science, \#P-299)*

Polymer tube cutters for $1 / 16$ " and 1/8" outer diameter tubing (IDEX Health \& Science, \#A-327)*

Spatula

Sharp hooked tweezers (Aldrich, \#T4912)*

Pliers*

9/16", 1/2", and 5/16" sized wrenches

Metal file

Bench vice

Deburring tool

Small drill bit

\section{(vi) In-line liquid-liquid separator}

Parts

Liquid-liquid membrane separator kit (Zaiput Flow Technologies, \#SEP-10)

Variable pore size PTFE hydrophobic replacement membranes (Zaiput Flow Technologies, 0.5 and $1.0 \mu \mathrm{m}$ pore sizes)

$2 \mathrm{x}$ Variable back pressure regulator kit containing a back pressure regulator and gas adapter (Zaiput Flow Technologies, \#BPR-10)

DuPont ${ }^{\circledR} 0.02$ " inner diameter, 1/16" outer diameter PFA tubing (IDEX Health \& Science, \#1512L)*

Ferrule set for 1/16" outer diameter tubing (IDEX Health \& Science, \#P-250)*

Super flangeless nuts for $\leq 1 / 16$ " outer diameter tubing (IDEX Health \& Science, \#P-141)*

Low-pressure PEEK unions for 1/16" outer diameter tubing (IDEX Health \& Science, \#P-702)* 
Tools

Polymer tube cutters for 1/16" and 1/8" outer diameter tubing (IDEX Health \& Science, \#A-327)*

Extender tool for standard head nuts (IDEX Health \& Science, \#P-299)*

Sharp hooked tweezers (Aldrich, \#T4912)*

Pliers*

3/32" Allen key

5/64" Allen key

\section{(vii) Drying unit}

Parts

Omnifit EZ chromatography column kit with $1 \mathrm{x}$ adjustable and $1 \mathrm{x}$ fixed end piece, $150 \mathrm{~mm}$ length (Omnifit, \#006EZ05-15-FF)

DuPont ${ }^{\circledR} 0.02$ " inner diameter, 1/16" outer diameter PFA tubing (IDEX Health \& Science, \#1512L)*

Ferrule sets for 1/16" outer diameter tubing (IDEX Health \& Science, \#P-250)*

Super flangeless nuts ${ }^{\mathrm{TM}}$ for $\leq 1 / 16$ " outer diameter tubing (IDEX Health \& Science, \#P-141)*

Low-pressure PEEK unions for 1/16" outer diameter tubing (IDEX Health \& Science, \#P-702)*

$4 \AA$ Å molecular sieves, beads, 4-8 mesh (Aldrich, \#208590)

Tools

Polymer tube cutters for 1/16" and 1/8" outer diameter tubing (IDEX Health \& Science, \#A-327)*

Extender tool for standard head nuts (IDEX Health \& Science, \#P-299)*

Sharp hooked tweezers (Aldrich, \#T4912)*

Pliers*

\section{Reagents}

Acetone for HPLC analysis $\geq 99.9 \%$ (Aldrich, \#270725) ! CAUTION acetone is highly flammable and volatile. Absolute ethanol, $\geq 99.8 \%$ (Aldrich, \#24102) ! CAUTION ethanol is highly flammable and volatile.

Toluene HPLC, 99.9\% (Aldrich, \#34866) ! CAUTION toluene is highly flammable.

\section{PROCEDURE}

\section{(i) Assembly of a reactor coil TIMING $10 \mathrm{~min}$ (supplemental video 1)}

Reactor coils form the basis of continuous-flow systems. In a continuous-flow synthesis, pumps (i.e. syringe pumps, HPLC pumps, piston pumps, or peristaltic pumps) drive fluid through reactors coils that can be heated, cooled and/or irradiated. The length, and volume of the reactor coil determines the length of time (i.e. the residence time) it takes for a fluid to pass through the reactor. Changing the flow rate of fluid through a reactor, or the length and volume of a reactor can change the residence time. The equations to calculate the required reactor coil length for a specific residence time are supplied in the supplementary information.

1| Cut DuPont ${ }^{\circledR}$ 0.02" inner diameter PFA tubing to the required length using polymer tube cutters. Use the equations found in the supplementary information to calculate the reactor volume required for a specific residence 
time at a desired flow rate. CRITICAL STEP Use polymer tube cutters to cut the PFA tubing to reduce the chance of reactor leaking. Polymer tube cutters provide a flush cut ensuring optimal sealing of the fitting.

2| Insert one end of the PFA tubing through a super flangeless nut ${ }^{\mathrm{TM}}$, ensuring that the thread of the nut is pointing towards the open end of the PFA tubing.

3| Slide the stainless steel ring of the ferrule set for 1/16" outer diameter tubing onto the PFA tubing using tweezers. Ensure the slanted part of the stainless steel ring is facing towards the open end of the PFA tubing, and the thicker portion towards the nut (Fig. 3A and D). CRITICAL STEP If the stainless steel ring is installed backwards, the reactor will not seal properly and, as a consequence, can leak.

4| Slide the yellow plastic component of the ferrule set for $1 / 16$ " outer diameter tubing onto the PFA tubing using tweezers. Ensure the cone portion of the yellow plastic component is facing the super flangeless nut ${ }^{\mathrm{TM}}$ and the stainless steel ring (Fig. 3B and D). CRITICAL STEP If the yellow plastic component is installed backwards, the reactor will not seal properly and, as a consequence, can leak.

5| Insert the end of the PFA tubing into a low-pressure PEEK union for 1/16" outer diameter tubing. Ensure the PFA tubing is constantly pushed into the low-pressure union while finger tightening the super flangeless nut ${ }^{\mathrm{TM}}$ (Fig. 3C). CRITICAL STEP If the PFA tubing is not constantly pressed into the union during tightening, the tubing may not be aligned with the ferrule during compression. This can lead to reactor failure and leaking.

6| Further tighten the super flangeless nut ${ }^{\mathrm{TM}}$ into the low-pressure union using the extender tool for standard head nuts. CRITICAL STEP Do not over tighten the ferrule as this will lead to deformation and/or cracking of the nut. This can lead to reactor failure and leaking.

7| Unscrew the flangeless nut from the union using the extender tool for standard head nuts. Ensure that the ferrule set is flush with the PFA tubing. CRITICAL STEP If this is not perfect, cut off the ferrule and the super flangeless nut ${ }^{\mathrm{TM}}$ and redo. Be mindful that cutting the tubing will decrease the residence time of the fluid in the reactor. ? TROUBLESHOOTING

8| Repeat steps 2-7 on the other end of the PFA tubing.

9| Coil the PFA tubing into a circle with a diameter less than the bath used to mediate the temperature of the reactor coil (Fig. 3E).

10| Use two cable ties to fasten opposite sides of the reactor coil into shape (Fig. 3F).

11 Finish the reactor coil by cutting the cable ties to a workable length (Fig. 3G). 


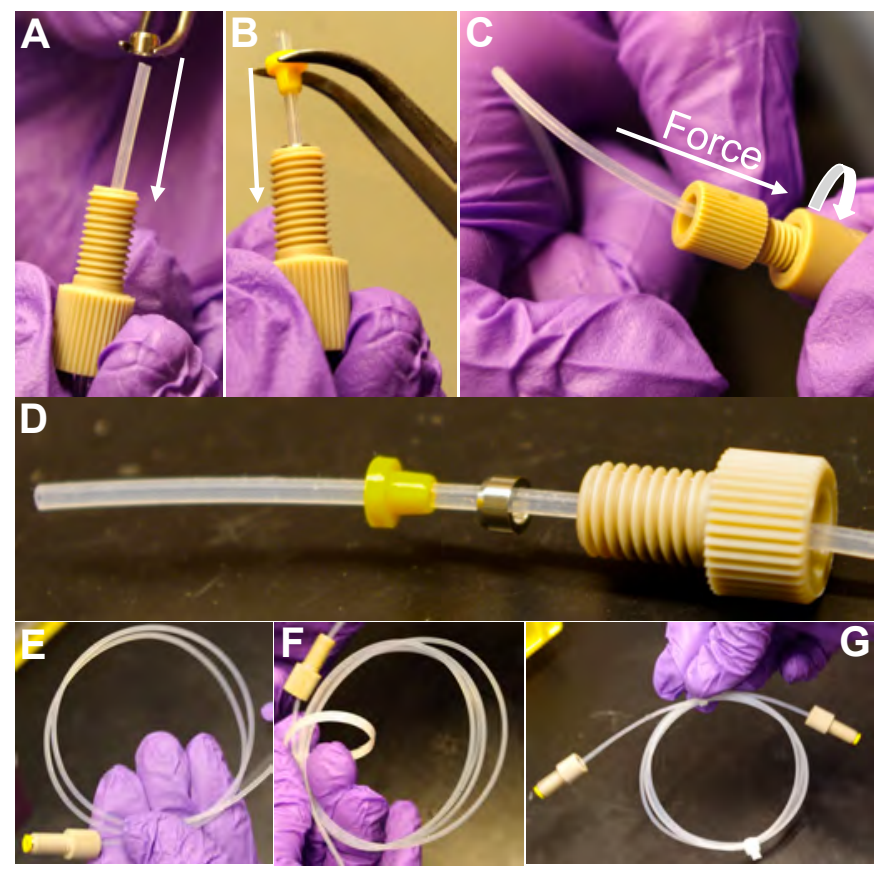

Figure 3| Reactor coil assembly (A) Slide the stainless steel ring of the ferrule set onto the PFA tubing using tweezers. Ensure that the smaller diameter face is pointing towards the end of the PFA tubing. (B) Slide the yellow plastic component of the ferrule set onto the PFA tubing with the neck positioned closest to the super flangeless nut ${ }^{\mathrm{TM}}$ and stainless steel ring. (C) Force the PFA tubing into the low-pressure union and finger tighten the super flangeless nut ${ }^{\mathrm{TM}}$ into the low-pressure union. (D) The correct order and orientation for the ferrule set on the PFA tubing. (E) Coil the reactor into a circular shape. (F) Use two cable ties to fasten the shape of the reactor coil. (G) Cut the cable ties to size to reveal the finished reactor coil.

\section{(ii) Assembly of a stainless steel syringe TIMING: $10 \mathrm{~min}$ (supplemental video 2)}

Stainless steel syringes are ideal for those new to the field of continuous-flow chemistry. Some reagents however are not compatible with stainless steel, and in this case, glass or plastic syringes should be used. It is worth noting that plastic and glass syringes are more affordable, but using stainless steel syringes allows fluid delivery at higher pressures ( $>25$ bar). Furthermore, glass syringes can shatter, and plastic syringes can crack if the system clogs, posing a safety concern. Although stainless steel syringes require greater financial investment, their long-term use and wide operational ability is highly advantageous. Accordingly, this part of the protocol describes the assembly of stainless syringes for use in a continuous-flow system. Here, $8 \mathrm{~mL}$ stainless steel syringes used due to their broad solvent capacity compared to the $20 \mathrm{~mL}$ stainless steel syringe; this relates to O-ring degradation. Furthermore, $8 \mathrm{ml}$ syringes are capable of dealing with higher-pressure systems, and as a consequence, fail less frequently. If a $20 \mathrm{~mL}$ stainless steel syringe is required, ensure that perfluoroelastomer barrel O-rings are installed (Harvard Apparatus, \#PY2 5013-089).

1) Unpack the contents of the stainless steel syringe kit (Fig. 4A). Contained within the kit should be a stainless steel syringe, its plunger, a metal ferrule set (component $2 \mathrm{a}$ and $\mathrm{b}$ ), a metal nut (component 1 ), and a syringe connector (component 3).

2| Connect, and finger tighten, the stainless steel syringe with the syringe connector. Use a bench vise to hold the syringe in place while performing this step (Figs. 4B and C). CRITICAL STEP Over tightening can deform the Oring in the syringe connector leading to failure. 
3| Cut a $30 \mathrm{~cm}$ long piece of DuPont ${ }^{\circledR} 0.02$ " inner diameter PFA tubing and ensure both ends have been cut flat with a polymer tube cutter. CRITICAL STEP Use polymer tube cutters to cut the PFA tubing to reduce the chance of reactor leaking. Polymer tube cutters provide a flush cut ensuring optimal sealing of the fitting.

4| Pass the PFA tubing through the metal nut (component 1) ensuring the threaded side of the nut is facing the end of the PFA tubing (Fig. 4D).

5| Slide the stainless steel ring (component 2a) onto the tubing using tweezers. Ensure the thicker side of the stainless steel ring is facing towards the nut, and the thinner side facing the end of the PFA tubing. Next, slide the stainless steel cone (component 2b) onto the PFA tubing using tweezers. Ensure the larger diameter side of the stainless steel cone is facing the metal nut and the stainless steel ring, and the smaller diameter face is pointing towards the end of the PFA tubing (Fig. 4D). Note that the Swagelok ferrules do not sit flush with the tubing as described for the super flangeless nut ${ }^{\mathrm{TM}}$ and ferrule in the previous section. Swagelok ferrules sit a few mm onto the PFA tubing. CRITICAL STEP If not correctly constructed the syringe can leak.

6| Insert the open end of the PFA tubing into the syringe connector (component 3). Ensure the PFA tubing is constantly pushed forced into the syringe connector and tighten the nut by hand (Fig. 4E). CRITICAL STEP If the PFA tubing is not constantly pushed into the syringe connector while tightening, the depth of the Swagelok ferrules may be incorrect and reactor leaking can occur.

7| Using two 5/16" wrenches to further tighten the metal nut onto the syringe connecter. CRITICAL STEP Do not over tighten as this can lead to constriction of the PFA tubing, and in extreme cases can break the PFA tubing. A properly tightened ferrule will remain in position when the nut has been disconnected from the syringe connector, but does not pinch tube PFA tubing.

8| Attach a super flangeless nut ${ }^{\mathrm{TM}}$ and ferrule set to the other end of the PFA tubing as previously described in steps 2-7 in reactor coil assembly (Fig. 4F). ? TROUBLESHOOTING

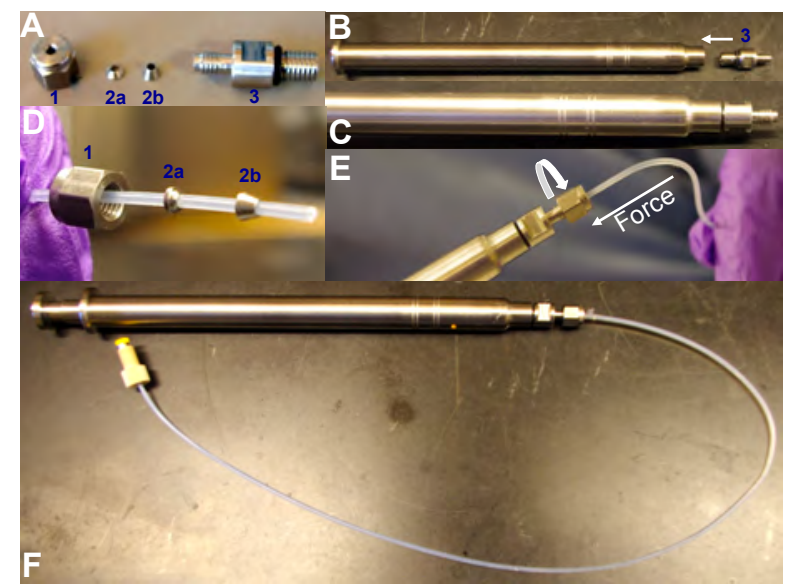

Figure 4| Stainless steel syringe assembly (A) Lay the components of the stainless steel syringe kit out to ensure all components are present (not shown are the syringe and its plunger). (B) Screw the syringe connector (component 3) into the syringe and tighten. (C) A photograph of the stainless steel syringe and the syringe connector joined. (D) The correct order, and orientation, of the components arranged onto the PFA tubing as described in step 5. (E) Ensure the PFA tubing is forced into the syringe connector (component 3) when tightening the metal nut as descried in step 7. (F) The finished stainless steel syringe. Note that the ferrule set, super flangeless nut ${ }^{\mathrm{TM}}$, and the PFA tubing can be replaced as needed.

\section{(iii) Assembly of a basic continuous-flow system TIMING 30 min}

This part of the protocol describes the assembly and operation of a simple continuous-flow system harnessing two syringe pumps at an elevated pressure. First, the pressurization of a Zaiput variable back pressure regulator is discussed. 
A variable back pressure regulator offers reaction flexibility, and in our experience, lasts longer than other back pressure regulators, but other options are available such as the fixed back pressure regulator cartridges from IDEX Health and Science (\#P-795 and P-764 for example). Operating under a back pressure allows solvents to be heated above their atmospheric boiling points while providing a smooth flow of fluid through the system. Second, the assembly of a continuous-flow system housing two syringe pumps, a T-mixer with check values, a single reactor coil and a back pressure regulator is detailed. This set up allows two solutions to be mixed, reacted, and then collected for analysis. Although a simple system, the skills in this section are invaluable for the assembly of more complex systems.

(a) Pressurization of the Zaiput variable back pressure regulator TIMING 10 min (supplemental video 3)

1| Unpack the contents of the variable back pressure regulator kit to reveal a back pressure regulator and a gas delivery tube.

2| Attach the gas delivery tube to a tank of compressed gas housing an adjustable regulator with a needle valve (Fig. 5A). Note that air is typically used, but $\mathrm{N}_{2}$ or argon can also be used.

3| Set the compressed gas regulator pressure to the desired pressure to be programmed into the variable back pressure regulator. For example, $100 \mathrm{psi}$ of compressed air equals a back pressure of $100 \mathrm{psi}$ in the variable back pressure regulator (Fig. 5B).

4| Fully open the valve on the back pressure regulator with a 1/10" screwdriver in an anti-clockwise motion. This will vent all the gas from the back pressure regulator setting the pressure to atmospheric (Fig. 5C). CRITICAL STEP Failure to vent the previous pressure within the back pressure regulator may lead to a higher than intended pressure due to prior pressure carrying over.

5| Connect the end of the gas delivery tube to the back pressure regulator and tighten by hand (Fig. 5C).

6| Fully open the needle valve on the compressed gas tank and allow pressure equilibration into the back pressure regulator for ten seconds. CRITICAL STEP Failure to allow full equilibration will lead to an inaccurate back pressure being used.

7| Using a 1/10" screwdriver, close the valve on the back pressure regulator by screwing in a clockwise motion (Fig. $5 \mathrm{C})$.

8| Close the needle valve on the compressed gas tank. CRITICAL STEP Closing the needle valve on the compressed gas tank before closing the valve on the back pressure regulator can result in an inaccurate pressure setting. ? TROUBLESHOOTING

9| Unscrew the back pressure regulator from the gas delivery tube. The back pressure regulator is now charged at the required pressure, and is ready for use. ? TROUBLESHOOTING

10| To change the pressure in the back pressure regulator, follow steps 3-9. For back pressure regulator use, see the below section on the assembly of a generic continuous-flow system. 


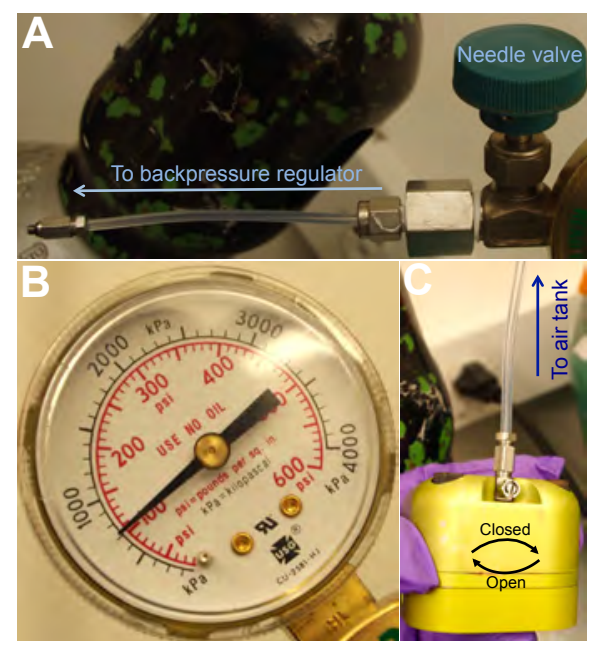

Figure 5| Pressurization of the back pressure regulator (A) Attach the gas delivery tube to the needle value on a compressed gas tank as shown. (B) Set the pressure in the compressed gas regulator to the pressure required in the back pressure regulator, shown here is 100 psi. (C) Open the valve on the back pressure regulator and attach to the gas delivery tube. Open the needle valve and allow equilibration for ten seconds. Close the back pressure regulator valve and then close the needle valve. Once the back pressure regulator is unscrewed from the gas delivery tube, it is ready for use.

\section{(b) Assembly of a generic continuous-flow system TIMING $20 \mathrm{~min}$ (supplemental video 4)}

1| Cut a $15 \mathrm{~cm}$ long piece of DuPont ${ }^{\circledR} 0.02$ " inner diameter PFA tubing using polymer tube cutters to ensure both ends have been cut flat. CRITICAL STEP Use polymer tube cutters to cut the PFA tubing to reduce the chance of reactor leaking. Polymer tube cutters provide a flush cut ensuring optimal sealing of the fitting.

2| To one end of this tubing add a super flangeless nut ${ }^{\mathrm{TM}}$ and a ferrule set as previously described in steps 2-7 of reactor coil assembly. ? TROUBLESHOOTING

3| Insert the super flangeless nut ${ }^{\mathrm{TM}}$ from the PFA tubing into the outlet port of the pressurized back pressure regulator. First tighten the nut using the extender tool for standard head nuts, and then using pliers. CRITICAL STEP Make sure the tubing is attached to the correct port of the back pressure regulator as indicated by the arrow (Fig. 6A). Furthermore, over tightening the super flangeless nut ${ }^{\mathrm{TM}}$ can lead to PFA tubing damage and cracking of the super flangeless nut ${ }^{\mathrm{TM}}$.

4| Gather the previously made reactor coil. Screw a PEEK T-junction mixer with 0.02 " inner diameter to one end of the reactor coil. Tighten the nut using the extender tool for standard head nuts (Fig. 6B). CRITICAL STEP Over tightening the super flangeless nut ${ }^{\mathrm{TM}}$ can lead to PFA tubing damage and cracking of the super flangeless nut ${ }^{\mathrm{TM}}$.

5| Attach the other end of the reactor coil to the back pressure regulator (Fig. 6D). To do this, insert the super flangeless nut $\mathrm{t}^{\mathrm{TM}}$ from the reactor coil into the remaining inlet port of the back pressure regulator. First tighten using the extender tool for standard head nuts, and then use pliers. CRITICAL STEP Over tightening the nut can lead to PFA tubing damage and cracking of the nut.

6| Attach standard 1/4-28 inline check valves to both remaining ports of the PEEK T-junction mixer. First tighten using the extender tool for standard head nuts, and then use pliers (Fig. 6C). In-line check valves ensure the fluid travels in the correct direction during system operation. CRITICAL STEP If no check valves are used, pressure changes can force solutions back into the stainless steel syringes during system equilibration; check values ensure correct fluid direction while system equilibration occurs. After equilibration, the fluid will proceed in the direction 
of least pressure resistance (the exit). If using a particularly corrosive solution, use non-metallic 1/4-28 inline check valves.

7| Fill the stainless steel syringes with the appropriate solutions. This is achieved by pulling back the syringe plunger with the open end of the PFA tubing resting in the fluid to be loaded. Withdraw the syringe plunger until the desired volume of fluid is reached. Examining the graduated marker on the syringe plunger will allow you to see what volume has been loaded. Remove the PFA tubing from the solution and expel any residual air by gently applying pressure to the syringe plunger and gently tapping the syringe. Attach the super flangeless nut ${ }^{\mathrm{TM}}$ from the stainless steel syringes PFA tubing into a standard 1/4-28 inline check valves. Tighten these super flangeless nuts $^{\mathrm{TM}}$ with the extender tool for standard head nuts, and then pliers (Fig. 6E). Load the stainless steel syringes into the syringe pumps ready for infusion (Fig. 6F). It is recommended to tighten all nuts used in the continuousflow system with pliers before system initiation. ? TROUBLESHOOTING

$\mathbf{8}$ If the reactor is to be heated or cooled, place the reactor coil into a bath, and reach the required temperature. In our experience, it is possible to heat PEEK fittings to $\sim 150{ }^{\circ} \mathrm{C}$ for extended periods of time without fail. However, if possible, leave the PEEK fitting outside of the oil bath to promote lifetime; the plastic part of the ferrule swells with extended exposure to heat. To ensure the reactor coil does not move in the oil bath, use binder clips to attach the reactor to the side of the oil bath. If using cryogenic temperatures, use the appropriate cryogenic bath solution to achieve the desired temperature. ! CAUTION Ensure that the binder clip is not compressing the tubing as this could lead to reactor clogging. ? TROUBLESHOOTING

9| Set the correct stainless steel syringe size on the screen of the pump, in this case, it is $8 \mathrm{~mL}$ (Fig. 6G). Next, set the required flow rate and then start syringe pump infusion. Collect the fluid exiting from the exit of the back pressure regulator. CRITICAL STEP It is important to immediately quench or analyze the solution exiting from the continuous-flow system to accurately determine the effect of the reaction conditions. Note that before collecting results for analysis; ensure that three residence times have elapsed as this ensures that the samples are representative of the continuous-flow system (i.e. the system has reached steady state). For example, if the residence time of the fluid is five minutes, do not start collection of samples for analysis before 15 minutes of equilibration time has elapsed. Be mindful that all components of the continuous-flow system contribute to the total residence time (back pressure regulator, T-junction, unions).

10| Once the experiment is completed, stop syringe pump infusions, and let the reactor cool down to ambient temperature. Unscrew one of the stainless steel syringes from the standard 1/4-28 inline check valves and exit the contents into the correct waste. Wash the syringe, re-grease the O-rings with Krytox grease, and add fresh solvent $(\sim 7 \mathrm{~mL})$ to the stainless steel syringe as described in step 7. Load this stainless steel syringe back into the syringe pump. Attach the super flangeless nut ${ }^{\mathrm{TM}}$ from the stainless steel syringe pumps into the inlet of the standard 1/4-28 inline check valve, tighten, and then start infusion. Flowing this fluid through the system will clean the reactor coil by pushing the reactants out of the system. CRITICAL STEP Cooling the system cool down to ambient temperature is fine if the reagents and products are soluble at room temperature. If they are not soluble, the reactor can clog. In this case, carefully clean the system at a temperature where the reagents/products are soluble. Safety should always be a prime consideration in this situation.

11| Once all of the solvent has been injected into the system, ensure that both syringes have stopped infusing and the syringe pump is turned off. Unscrew the stainless steel syringes from the standard 1/4-28 inline check valves and eject their contents into the correct waste. ! CAUTION Disconnecting a high-pressure system can result in uncontrollable fluid ejection. To avoid this, first open the valve of the back pressure regulator to reduce the 
system to ambient pressure. The solution will exit the exit port of the back pressure regulator. This solution needs to be collected for waste.

12| Wash the stainless steel syringes with water and soap and then dry with acetone. Before using again ensure that Krytox grease has been added to the O-rings of the stainless steel syringe plunger.

13| Disconnect the reactor coil from the back pressure regulator and remove from the bath. Lay the reactor on paper towels to absorb the oil and unscrew the PEEK T-junction mixer.

114| Blow compressed air through the reactor coil to remove residual solvent.

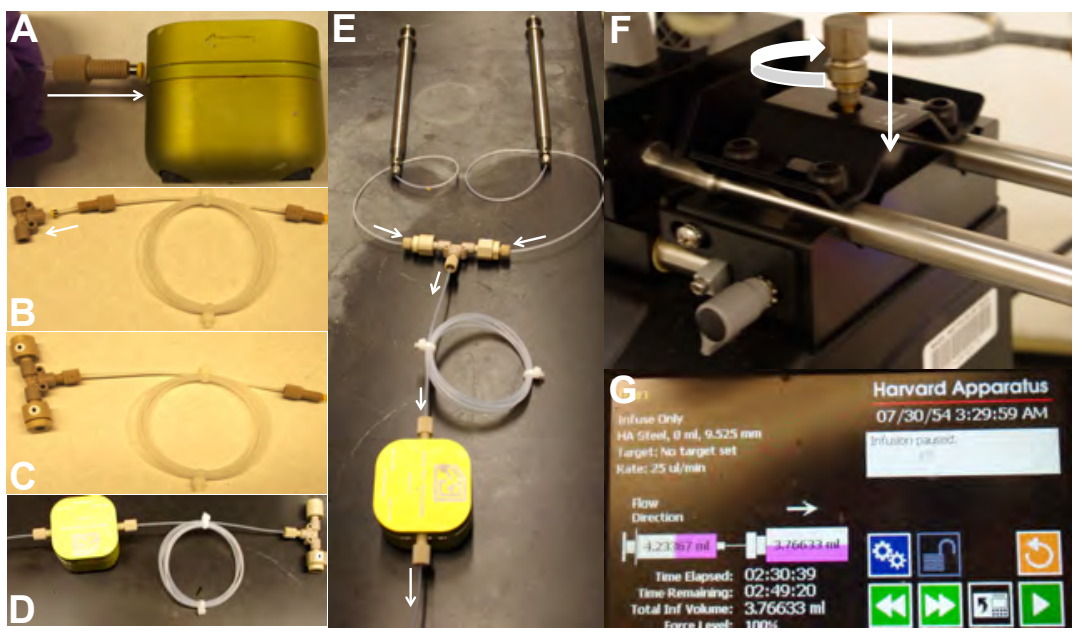

Figure 6| Continuous-flow system assembly (A) Insert the super flangeless nut ${ }^{\mathrm{TM}}$ from the $15 \mathrm{~cm}$ PFA tubing into the back pressure outlet valve as directed by the arrow. Tighten the super flangeless nut ${ }^{\mathrm{TM}}$ with pliers to ensure a tight seal. (B) Connect the required reactor to be used to a PEEK T-junction mixer and tighten with the extender tool for standard head nuts. (C) Attach standard 1/4-28 inline check valves to the PEEK T-junction mixer and ensure the arrows on the check valves are pointing towards in the direction of the fluid flow. (D) Attach the super flangeless nut ${ }^{\mathrm{TM}}$ from the remaining end of the reactor coil to the back pressure regulator inlet port, and tighten with pliers. (E) Attach the stainless steel syringes to standard 1/4-28 inline check valves and tighten with pliers. (F) Insert the stainless steel syringes into the Harvard Syringe pumps as shown and compress the pad to secure the syringes. (G) Program the syringe pump to infuse at a particular flow rate (entitled "Rate" here).

\section{Advanced Procedures}

\section{Improved mixing in a continuous-flow system}

After the use of a basic continuous-flow system, more intense mixing may be required. Although solutions mix efficiently in the PEEK T-junction mixer, some situations generate large slugs of two immiscible fluids (slug flow). Further micromixing through a static mixer or packed bed reactor can increase reaction efficiencies. In the first instance, incorporate a static mixer after the PEEK T-junction mixer, and before the reactor coil. However, if still ineffective, pass the fluid through a packed bed reactor housing sand, stainless steel, or glass beads. Packed bed reactors provide efficient and sustained mixing, and have been utilized in several continuous-flow syntheses. ${ }^{36}$ This section of the protocol describes assembly of a static mixer and packed bed reactor housing sand.

\section{(iv) Assembly of a static mixer TIMIING $10 \mathrm{~min}$ (supplemental video 5)}

1| Cut a $10 \mathrm{~cm}$ piece of DuPont ${ }^{\circledR} 0.062$ " inner diameter, $1 / 8$ " outer diameter PFA tubing using polymer tube cutters. CRITICAL STEP Use polymer tube cutters to cut the PFA tubing to reduce the chance of reactor leaking. Polymer tube cutters provide a flush cut ensuring optimal sealing of the fitting. 
2| Remove the Teflon static mixer from its packaging (Fig. 7A) and insert into the PFA tubing using tweezers (Fig. 7C). ! CAUTION The static mixer is sensitive and too much pressure will bend and snap it - be careful.

3| Using the end of the tweezers, gently push the Teflon static mixer down the PFA tubing until a headroom of $\sim 1$ $\mathrm{cm}$ is visible (Fig. 7D). If only a small static mixer is required, then proceed to the next step. If more extensive mixing is required, add more static mixers on top of each other to create a larger mixing region. If more than three static mixers are required we suggested try a packed bed reactor (see below). ? TROUBLESHOOTING

4| Add a ferrule set for 1/8" outer diameter tubing (component 2 and 3, Fig. 7B) and a super flangeless nut ${ }^{\mathrm{TM}}$ for $\leq 1 / 8$ " outer diameter tubing (component 1, Fig. 7B) to the PFA tubing using tweezers. Ensure that the orientation of the components is the same as shown in Fig. 7E. Tighten and secure the ferrule set as previously described in steps 2-7 of reactor coil assembly.

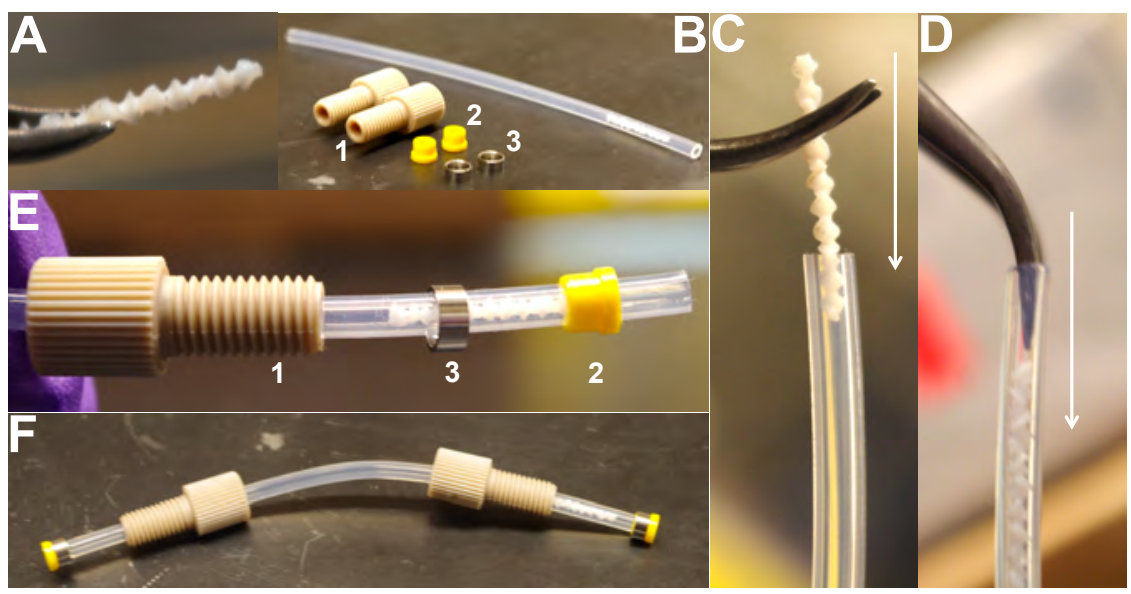

Figure 7| Assembly of a static mixer. (A) The Teflon static mixer from packaging. (B) PFA tubing housing the static mixer, a 1/8" super flangeless nut ${ }^{\mathrm{TM}}$ (component 1) and a 1/8" ferrule set (components 2 and 3). (C) Insert the Teflon static mixer into the PFA tubing using tweezers. (D) Further insert the Teflon static mixer using the end of the tweezers until $\sim 1 \mathrm{~cm}$ into the PFA tubing. (E) The correct order and orientation of the components as described in step 4 above. (F) The complete static mixer.

\section{(v) Assembly of a packed bed reactor TIMING $30 \mathrm{~min}$ (supplemental videos 6, 7, 8 and 9)}

1| Gather two Swagelok stainless zero volume reducing union $1 / 4$ " outside diameter and lay the parts out as displayed in Fig. 8A.

2| Mount the seamless stainless steel tubing into a bench vise and mark out a $10 \mathrm{~cm}$ portion (Fig. 8B). Place the metal tube cutter around the point to be cut, and tighten. Rotate the metal tube cutter around the stainless steel tubing and at every ten turns, tighten the tube cutter further to ensure the blade of the tube cutter remains in contact with the stainless steel tubing (Supplemental video 6). Keep rotating the metal tube cutter around the stainless steel tubing until cut. If the metal tubing is moving then the tube cutters are to tight. In this case, loosen the tube cutters and tighten less every ten turns.

3| File both ends of the cut stainless steel tubing flat using a metal file (Supplemental video 7). Then, deburr the opening using a deburring tool to ensure the inside surface is flush with the rest of the stainless steel tube.

4| Unscrew the metal nut (component 0) from the union 1/4" ports (component 1) and insert a $10 \mu \mathrm{m}$ stainless steel frit. Push the frit to the bottom using tweezers, and then reattach the metal nut (Fig. 8E). CRITICAL STEP Inserting the frit into the 1/4" ports (component 1 ) at this stage avoids incorrect spacing in step 5.

$\mathbf{5}$ To both ends of the stainless steel tubing add the Swagelok union parts in the order and orientation shown in Fig. 8C.

First slide the metal nut (component 2) onto the tube with the threads pointing towards the end of the tube. Next, slide 
the ring component of the ferrule set (component 3) onto the tube with the larger diameter face pointing towards the threads of the metal nut. Then, slide the cone component of the ferrule set (component 4) onto the tube with the larger diameter face pointing towards the ring component (component 3) and the metal nut (component 2). Finally, slide the Swagelok union (component 1) onto the tube with the threads facing the ferrule set and the metal nut.

$6 \mathbf{l}$ Compress the components and tighten by hand in a clockwise motion to secure. Mount the stainless steel tubing into the bench vise and use 1/2" and 9/16" wrenches to tighten the nut into the Swagelok union further. CRITICAL STEP This needs to be tight; the packed bed mixer is under pressure.

7l Unscrew the smaller metal nut (component 0) and lay the contained ferrule set out as shown in Fig. 8D. Be careful to not lose the components inside, they can sometimes slide out.

81 Cut $2 \times 10 \mathrm{~cm}$ long pieces of DuPont ${ }^{\circledR} 0.02$ " inner diameter PFA tubing with a polymer tube cutter to ensure both ends of the tubing are flat. These will serve as the tubing connecting the packed bed mixer to the other parts of the continuous-flow system. CRITICAL STEP Use polymer tube cutters to cut the PFA tubing to reduce the chance of reactor leaking. Polymer tube cutters provide a flush cut ensuring optimal sealing of the fitting.

91 To one end of the PFA tubing, add components 5,6, and 7 as shown in Fig. 8F (Supplemental video 8). First slide the metal nut (component 5) onto the PFA tubing with the thread facing the end of the PFA tubing. Next, slide on the metal ring (component 6) with the larger diameter side facing the threads of the metal nut, and the small diameter facing the end of the PFA tubing. Finally, add the metal cone (component 7) with the larger diameter side facing the threads of the metal nut and the metal ring, and the smaller face pointing towards the end of the PFA tubing.

10I Insert this end of the PFA tubing into the Swagelok union (component 1) and apply pressure while simultaneously finger tightening. Mount the reactor back into the bench vise and tighten using 9/16" and 5/16" sized wrenches (Fig. 8G). ? TROUBLESHOOTING

11I Repeat steps 9-10 on the other side of the stainless steel tube to ensure both sides of the packed bed reactor now have PFA tubing attachments.

12I To both ends of the PFA tubing add a super flangeless nut ${ }^{\mathrm{TM}}$ and ferrule set using the method previously described in steps 2-7 in the reactor coil assembly section (Fig. 8I).

13I Unscrew the metal nut (component 2) from the Swagelok union (component 1) to reveal an opening into the stainless steel tube.

14I To create a funnel for loading, take a $3 \mathrm{~mL}$ disposable plastic syringe and completely remove the plunger. Insert the small end of the syringe into the stainless steel tube so that it is held firm.

15I Add sand into the stainless steel tube while simultaneously tapping the stainless steel tubing and the syringe with a spatula to ensure good packing and sand release (Supplemental video 9). Other materials can be used in the packed bed reactor such stainless steel chippings, however, use of very small packing materials can cause a large pressure increase leading to syringe pump failure. A general rule is to use a material that will require ten units or more to span the diameter of the stainless steel tubing. For example, if the internal diameter of the packed bed reactor is 0.180 ", then sand particles with a diameter of $\leq 0.0180$ " should be used.

161 Use the flat back end of a drill piece to pat down the sand to ensure complete and firm packing.

17I Place you finger on top of the filled stainless steel tubing and subject the surrounding nuts to compressed air to remove any loose sand. CRITICAL STEP Sand caught in the metal nut can lead to an inefficient seal.

18| Screw the metal nut (component 2) into the Swagelok union (component 1) using 1/2 and 9/16" wrenches to ensure a tight fitting. The packed bed reactor is now complete and ready to use. To change the material in the packed bed reactor, repeat steps 13-18 ensuring the sand is disposed into solid waste and that the column is washed with a 
solvent of choice. Unpacking the column is best when the material contained within the column is dry. ? TROUBLESHOOTING

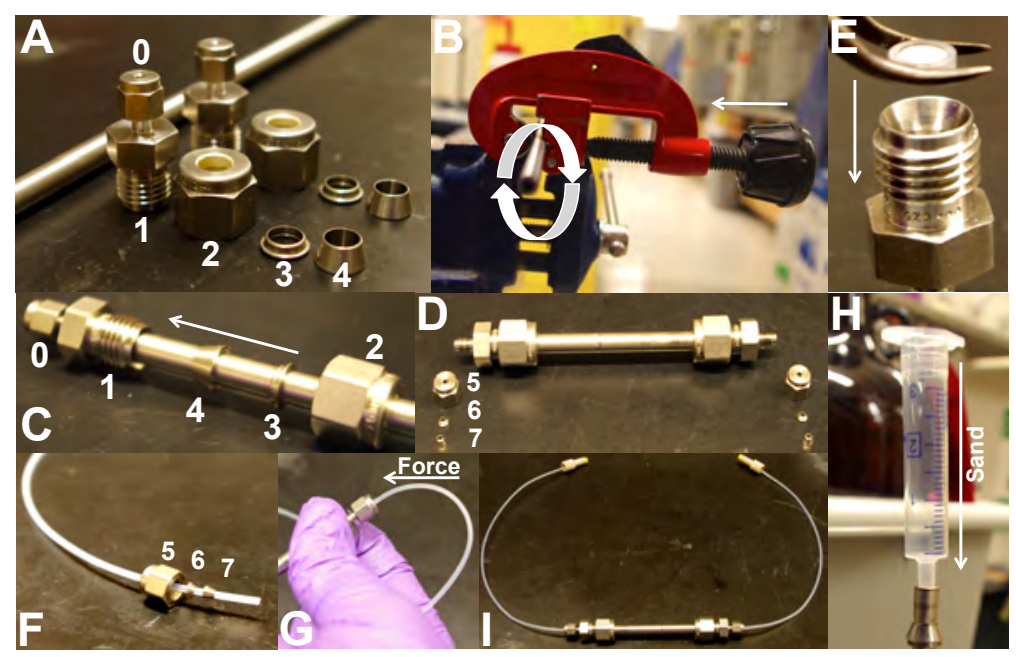

Figure 8| Packed bed reactor assembly (A) The components of the Swagelok stainless steel zero volume reducing union laid out in a workable order, and the seamless stainless steel tubing in the background. (B) After the seamless stainless steel tubing has been clamped into the place, use a metal tube to cut the stainless steel tubing to the required length. (C) The correct order and orientation in which to lay the components of the Swagelok stainless zero volume reducing union onto the stainless steel tubing. (D) After unscrewing the small metal nut (component 0) from the Swagelok union (component 1), place ferrule set in this workable order. (E) Place the $10 \mu \mathrm{m}$ stainless steel frit into the Swagelok union (component 1) using tweezers. (F) The correct order, and orientation, to slide the components onto the PFA tubing. (G) Apply force to the PFA tubing when screwing the small metal nut (component 0) into the Swagelok union (component 1), this ensures a good attachment. (I) The complete packed bed reactor. Connecting the super flangeless nut ${ }^{\mathrm{TM}}$ shown on both ends on the packed bed reactor allow it to be inserted into any part of the continuous-flow system. (H) Use a $3 \mathrm{~mL}$ plastic syringe to act as a funnel for the addition of material to the packed bed reactor.

\section{(b) In-line purification of intermediate compounds}

In multi-step continuous-flow transformations, the purification of intermediate compounds is vital to ensure high reaction yields. Liquid-liquid extractions can be achieved in-line by injecting water into the continuous-flow stream through a T-mixer and then directing the stream into a liquid-liquid separator. Here, the organic phase passes through a semi-permeable membrane and enters new PFA tubing. The aqueous phase does not pass through the membrane, and enters separate PFA tubing. If water-soluble salts or impurities are present they will remain in the aqueous phase, purifying the organic stream to some extent. The organic phase (or aqueous phase) can be channeled into another reactor coil for a sequential reaction, or can be collected. This next section describes the assembly and cleaning of a Zaiput liquid-liquid separator.

\section{(vi) Use of an in-line liquid-liquid separator TIMING $30 \mathrm{~min}$}

If using a new in-line liquid-liquid separator proceed to step 11.

1| Remove the six screws (three per side) from both sides of the separator using a 3/32" Allen key as depicted in Fig. 9A.

2| Open the separator being careful of any residual fluid that may be present.

3| If the membrane if fouled, use tweezers to remove it. Discard the fouled membrane into solid waste (Fig. 9B). In this sense, fouled describes a chemical degradation or perturbation of the membrane. For example, solids can 
collect on the membrane rendering it inefficient, or chemicals can coat the membrane leading to failure. Regular inspection of the membrane is suggested.

4| Unscrew the metal disk surrounding the diaphragm with a 5/64" Allen key (Fig. 9B).

5| Carefully remove the diaphragm with tweezers. CRITICAL STEP Damaging this part will cause the separator to fail.

6| Wash all of the components and the device with soapy water, ethanol, and finally acetone. Leave the device to dry for a few hours, using a paper towel to remove the majority of the water.

7| Place a new precut porosity membrane from Zaiput Flow Technologies onto the device as depicted in Fig. 9E. Alternatively, sheets of porosity membrane can be purchased, and then cut in to the correct size using a scalpel. CRITICAL STEP The rough side of the membrane must face upwards. If this membrane is placed on the component with the seal the wrong way up, separation can fail.

8| Insert the diaphragm (a new one if the old one is damaged) back into the metal disk, ensuring that when it is placed back into the device the raised face is pointing into the concave part of the separator (Fig. 9D).

9| Screw the metal disk into place, being careful not to over tighten the screws by using the cross tightening pattern.

10| Place the lid of the separator into place and insert all six screws with a 3/32" Allen key. Tighten each screw gently to ensure an even fit by using the cross tightening pattern.

11 Cut $3 \times 10 \mathrm{~cm}$ pieces of DuPont ${ }^{\circledR} 0.02$ " inner diameter PFA tubing and cut both ends using polymer tube cutters. CRITICAL STEP Use polymer tube cutters to cut the PFA tubing to reduce the chance of reactor leaking. Polymer tube cutters provide a flush cut ensuring optimal sealing of the fitting.

12| Attach super flangeless nuts ${ }^{\mathrm{TM}}$ and ferrule sets to both ends of the PFA tubes using the method previously described in steps 2-7 of the reactor coil assembly section.

13 Attach the PFA tubes to the three separator inlets. Insert the super flangeless nut ${ }^{\mathrm{TM}}$ into the entry of the separator and tighten with pliers to ensure a tight fitting (Fig. 9F). CRITICAL STEP These super flangeless nuts ${ }^{\mathrm{TM}}$ have to be tight otherwise the separator will leak.

14| Attach a 20 psi back pressure regulator to the aqueous stream and an 21 psi charged back pressure regulator to the organic stream as depicted in Fig. 9G. CRITICAL STEP These values are not absolute and depending upon the continuous-flow setup, values will vary. In the first instance, if just using a separator at the end of the system, see if separation is achieved with no back pressure on either of the exiting streams. Importantly, the pressure on both sides must be near equal. Thus, if the organic side leads into a packed bed reactor and a drying unit, this will add pressure to the organic side and must be counteracted by placing a back pressure on the aqueous side. ? TROUBLESHOOTING

15. Flow through toluene $(50 \mathrm{~mL})$ and then water $(50 \mathrm{~mL})$ to equilibrate the device at a flow rate of $500 \mu \mathrm{L} / \mathrm{min}$. CRITICAL STEP Pre-charging the membrane in this manner will improve the separation efficiency. 


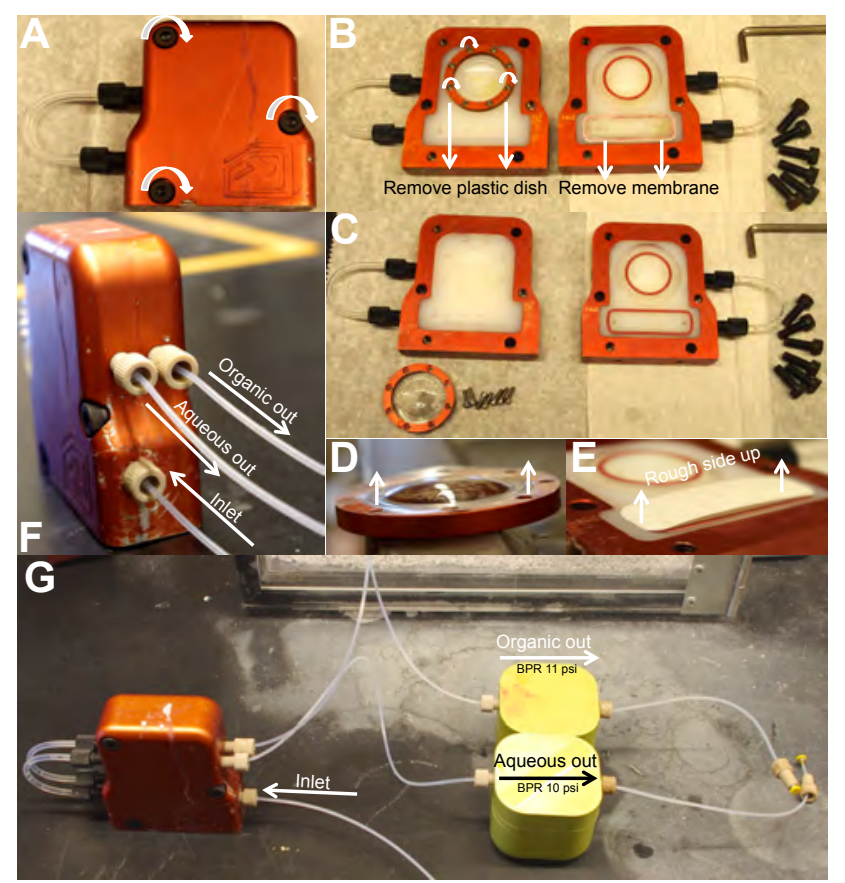

Figure 9| Assembly of a liquid-liquid separator and incorporation into a continuous-flow system. (A) Unscrew the three screws on both sides of the separator using a 3/32" Allen key. (B) Remove the fouled membrane and discard into solid waste. Unscrew the circular metal housing using a 5/64" Allen key. (C) This fully deconstructed separator can be cleaned with hot soapy water, then ethanol, then acetone. (D) When constructing the separator, ensure the raised face of the diaphragm faces towards the separator. (E) When replacing the membrane, ensure the rough side of the membrane is upwards. (F) The stream to be separated enters the separator from the bottom. The organic phase passes through the membrane into another channel and is collected on the opposite side of the separator. The aqueous phase remains in the same channel, and thus remains on the same side of the separator. (G) The separator incorporated into a continuous-flow system. Normally, a slight excess back pressure on the organic stream facilitates separation. For further information see www.zaiput.com.

\section{(b) Drying the continuous-flow stream}

A subsequent reaction in a multi-step continuous-flow sequence can require solvent with decreased water content. Utilizing a liquid-liquid separator in a prior step can result in an organic solvent having a $\mathrm{H}_{2} \mathrm{O}$ content of 1 55,000 ppm (2-methyl THF for example). Passing the organic phase through a drying unit can decrease the $\mathrm{H}_{2} \mathrm{O}$ content to $\sim 300 \mathrm{ppm}$. The $\mathrm{H}_{2} \mathrm{O}$ content of the organic solvent entering the drying unit will determine the lifetime of the unit. As a rough guide; 2-methyl THF with a $\mathrm{H}_{2} \mathrm{O}$ content of $\sim 5 \mathrm{ppm}$ can be dried to $350 \mathrm{ppm}$ for a lifetime $\sim 6 \mathrm{~h}$, while a $\mathrm{H}_{2} \mathrm{O}$ content of $50,000 \mathrm{ppm}$ can be dried to $350 \mathrm{ppm}$ for $\sim 90 \mathrm{~min}$. The performance of the drying unit is dependent upon the length of the column, and the shape and size of the molecular sieves housed within. Ensuring the organic phase is as dry as possible before entering the drying unit ensures its lifetime. This final section describes the assembly and use of a drying unit.

\section{(vii) Assembly of a drying unit TIMING $24 \mathrm{~h}$}

1| Add $10 \mathrm{~g}$ of $4 \AA$ molecular sieves to a $100 \mathrm{ml}$ glass beaker and heat at $140{ }^{\circ} \mathrm{C}$ for at least $16 \mathrm{~h}$. Steps $2-7$ can be achieved while heating the $4 \AA$ molecular sieves.

2| Unpack the contents of an Omnifit chromatography column kit (150 mm length). Remove the retaining cap from the column, and fully extend the adjustable end piece (Fig. 10A). 
3| Cut 2 x $15 \mathrm{~cm}$ pieces of DuPont ${ }^{\circledR} 0.02$ " inner diameter PFA tubing and cut flat the ends of the tubing with a polymer tube cutter. CRITICAL STEP Use polymer tube cutters to cut the PFA tubing to reduce the chance of reactor leaking. Polymer tube cutters provide a flush cut ensuring optimal sealing of the fitting.

4| To both pieces of $15 \mathrm{~cm}$ PFA tubing attach a blue plastic nut with a ferrule set (contained in the column kit, but a super flangeless nut ${ }^{\mathrm{TM}}$ can also be used) to one end of the tubing, and a super flangeless nut ${ }^{\mathrm{TM}}$ with a ferrule set to the other end of the PFA tubing using the method previously described in steps 2-7 in the reactor coil assembly section (Fig. 10D).

5| Attach one of the $15 \mathrm{~cm}$ PFA tubes to the connection cap (found in the column kit) by inserting the blue plastic nut from the PFA tubing into the blue connection cap and tightening using pliers. Attach the connection cap to the fully extendable end piece and tighten (Fig. 10F).

6| Thread the nut from the extendable end piece onto the glass column. Turn in a clockwise motion until firm, but not tight (Fig. 10F).

7| Twist the upper portion of the nut counter clockwise to lower the variable length section. Once the desired depth has been achieved, fully tighten the lower nut onto the glass column in a clockwise fashion. To remove the extendable end piece, reverse steps 6 and 7.

8| Attach the other $15 \mathrm{~cm}$ PFA tube to a connection cap by inserting the blue plastic nut from the PFA tubing into the blue connection cap and tightening using the pliers. Attach the connection cap to the retaining cap and tighten (Figs. 10C and B).

9| Fill the chromatography column to $95 \%$ volume (130 mm deep) with $4 \AA$ molecular sieves directly from the oven and immediately cap with the retaining head Figs. 10H. ! CAUTION Use laboratory grade oven gloves as this glass beaker is extremely hot. We suggest clamping the column in an upright position to make this easier (Fig. 10G).

10| Screw the retaining head into the column until firm. ! CAUTION Over tightening will cause the glass column to crack.

11 Connect the PFA tubing attached to the adjustable end piece to another part of the flow system by inserting the super flangeless nut ${ }^{\mathrm{TM}}$ into a low-pressure PEEK union for 1/16" outer diameter tubing. The other side of this lowpressure PEEK union can be connected to any part of the continuous-flow system. ? TROUBLESHOOTING

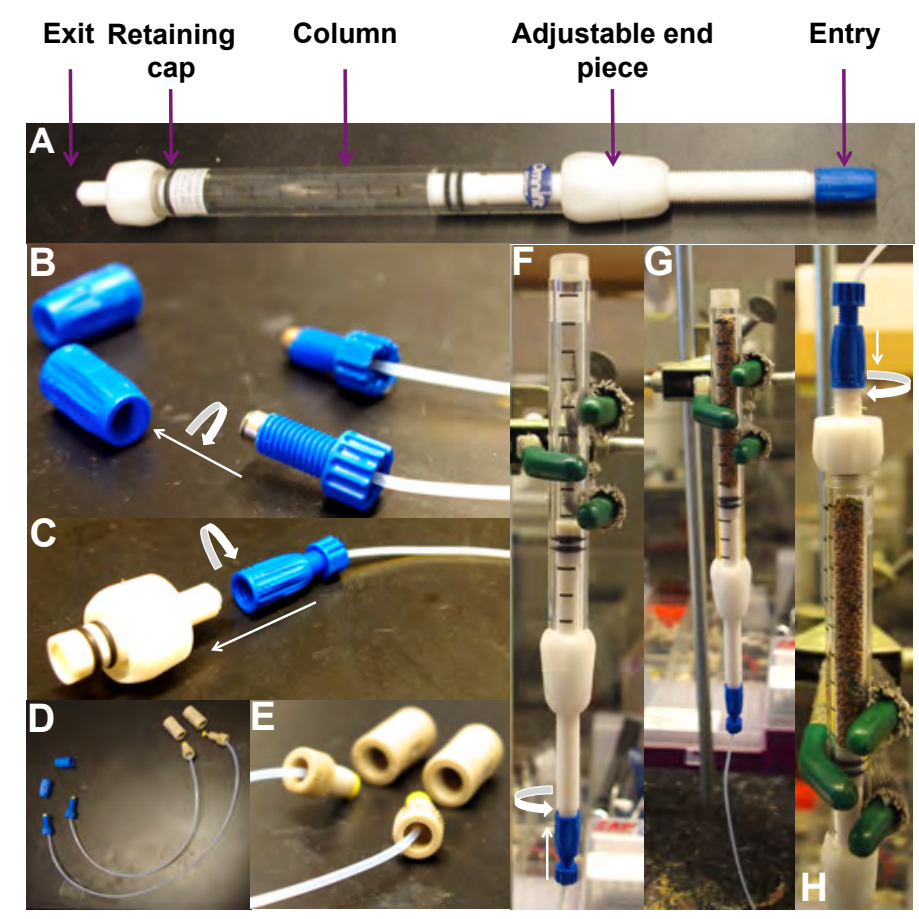


Figure 10| Assembly of a drying unit. (A) A $150 \mathrm{~mm}$ Omnifit column as received. Highlighted are the key components described in this protocol. (B) Screw the blue nut from one of the PFA tubes into the blue connection cap and tighten. (C) Screw one of the connection-cap modified PFA tubes to the retaining cap and tighten. (D and E) The components used to create the modified PFA tubing as described in step 4. Shown are the two modified PFA tubes, $2 \mathrm{x}$ connection caps, and two low-pressure unions. (F) The Omnifit column with PFA tubing attached to the adjustable end piece (G) Fill the Omnifit column with activated $4 \AA$ molecular sieves to $95 \%$ of the volume as described in step 9. Note that the choice of molecular sieves depends upon the solvent to be dried. (H) Insert the retaining cap and tighten to complete the drying column.

\section{EXAMPLE REACTION}

The reaction below is used in our laboratory to teach continuous-flow synthesis. In this experiment, 4chlorobenzenesulfonyl chloride $\mathbf{1}$ and dibenzylamine $\mathbf{2}$ react to yield sulfonamide $\mathbf{3}$ in a single reactor with an in line quench (Fig. 11). Several skills including: reactor construction, charging of a back pressure regulator, the assembly of stainless steel syringes, the assembly of a continuous-flow system with multiple junctions, and yield determination are described.

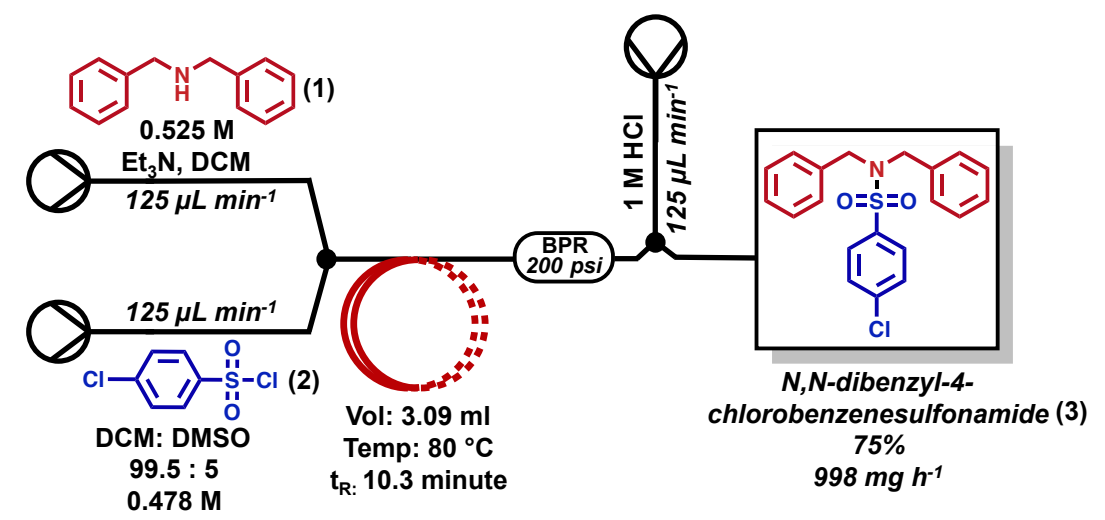

Figure 11| Synthesis of sulfonamide 3 from dibenzylamine 1 and 4-chlorobenzenesulfonyl chloride 2. This continuous-flow synthesis produces $998 \mathrm{mg} \mathrm{h}^{-1}$ of $\mathbf{3}$ through use of a single reactor coil and in-line quench.

\section{Materials}

DuPont ${ }^{\circledR}$ 0.02" inner diameter, 1/16" outer diameter PFA tubing (IDEX Health \& Science, \#1512L)

Polymer tube cutters for $1 / 16$ " and 1/8" outer diameter tubing (IDEX Health \& Science, \#A-327)

Ferrule sets for 1/16" outer diameter tubing (IDEX Health \& Science, \#P-250)

Super flangeless nuts ${ }^{\mathrm{TM}}$ for $\leq 1 / 16$ " outer diameter tubing (IDEX Health \& Science, \#P-141)

Low-pressure PEEK unions for 1/16” outer diameter tubing (IDEX Health \& Science, \#P-702)

Extender tool for standard head nuts (IDEX Health \& Science, \#P-299)

Cable ties (Staples, \#192314)

Sharp hooked tweezers (Aldrich, \#T4912)

Pliers

Variable back pressure regulator kit containing a back pressure regulator and gas adapter (Zaiput Flow Technologies, \#BPR-10)

PEEK Y-Assembly PEEK mixer for 1/16” outer diameter tubing, 0.60” thru hole (IDEX Health \& Science, \#P-514) $3 \times 8 \mathrm{~mL}$ stainless steel syringe kit with a 1/16" nut (Harvard apparatus, \#702267)

2 x Syringe pumps (Harvard PhD syringe pump, \#70-3005) 
Krytox LVP grease (Aldrich, \#Z273546)

$2 \times$ Hot plate (Heindolph ${ }^{\mathrm{TM}}$ MR Series Magnetic Stirrer Hotplate)

Oil bath (30 $\mathrm{cm}$ diameter)

Silicon oil with a temperature range from $-50^{\circ} \mathrm{C}$ to $+200{ }^{\circ} \mathrm{C}$ (Aldrich, \#85409-1L)

3 x 25 mL Glass beaker (Aldrich, \#BR91214)

2 x 10 mL Volumetric flask (Aldrich, \#Z326178)

$2 \times 250 \mathrm{~mL}$ Volumetric flask (Aldrich, \#Z326798)

$125 \mathrm{~mL}$ Separatory funnel (Aldrich, \#Z550582)

Powder funnel with a ST/SN joint (Aldrich, \#Z517828)

$250 \mathrm{~mL}$ Round bottom flask (Aldrich, \#Z414506)

Whatman ${ }^{\circledR}$ qualitative filter paper, Grade 1 (Aldrich, \#Z274844)

Whatman ${ }^{\circledR}$ weighing paper (Aldrich, \#WHA10347670)

Ohaus New Explorer weighing balance (Aldrich, \#Z760420)

12“ Spatula (Aldrich, \#Z283274)

1/2” PTFE stir bar (Aldrich, \#Z126942)

20-200 $\mu \mathrm{L}$ Pipette and disposable tips (Aldrich, \#Z710180)

$1000 \mu$ L Pipette and disposable tips (Aldrich, \#Z710199)

Glass Pasteur pipette (Aldrich, \#CLS709B9)

Pasteur pipette rubber bulb (Aldrich, \#Z111589)

$2 \times$ Binder clips (Staples, \#378813)

2 x Clamp

$10 \mathrm{~mL}$ Disposable plastic syringe

Hypodermic needles

Rotary evaporator

\section{Reagents}

Dibenzylamine, 97\% (Aldrich, \#D34108-100 g, CAS: 103-49-1) !CAUTION This chemical is corrosive and toxic. It should always be handled in a fume hood with the appropriate personal protective equipment.

4-Chlorobenzenesulfonyl chloride, 97\% (Aldrich, \#133698-100 g, CAS: 98-60-2) !CAUTION This chemical is corrosive and toxic. It should always be handled in a fume hood with the appropriate personal protective equipment.

Triethylamine, $>99.5 \%$ (Aldrich, \#471283-100 mL, CAS: 121-44-8) !CAUTION This chemical is corrosive, toxic and flammable. It should always be handled in a fume hood with the appropriate personal protective equipment.

Anhydrous dichloromethane (DCM), $>99.8 \%$ (Aldrich, \#270997-100 mL, CAS: 75-09-2) !CAUTION This chemical is toxic. It should always be handled in a fume hood with the appropriate personal protective equipment.

Anhydrous dimethyl sulfoxide (DMSO), >99.9\% (Aldrich, \#276855-100 mL, CAS: 67-68-5).

Hexanes, >97\% (Aldrich, \#34859-1 L, CAS: 110-54-3) !CAUTION This chemical is toxic, flammable and hazardous to the aquatic environment. It should always be handled in a fume hood with the appropriate personal protective equipment.

Ethyl acetate, 99.7\% (Aldrich, \#34858-1 L, CAS: 141-78-6) !CAUTION This chemical is toxic and flammable and should always be handled in a fume hood with the appropriate personal protective equipment. 
Chloroform- $d\left(\mathrm{CDCl}_{3}\right), 100 \%, 99,96$ atom\% D (Aldrich, \#151858-10 G, CAS: 865-49-6) !CAUTION This chemical is toxic. It should always be handled in a fume hood with the appropriate personal protective equipment.

Silica column (Biotage ${ }^{\circledR}$ SNAP 25 g KP column, \#FSK0-1107-0025).

Magnesium sulfate, anhydrous and $>99.5 \%$ (Aldrich, \#M7506-500G, CAS: 7487-88-9).

1 M Hydrochloric acid (Aldrich, \#H9892-100 ML, CAS: 7647-01-0).

\section{PROCEDURE}

\section{(i) Assembling the continuous-flow system TIMING $30 \mathrm{~min}$}

1| Using Part 1 “Assembling of a reactor coil", assemble a reactor coil constructed from 0.02 " inner diameter DuPont ${ }^{\circledR}$ tubing with a length of $1524 \mathrm{~cm}$ (50 foot, $3.089 \mathrm{~mL})$.

2| To one end of the constructed reactor coil attach a PEEK Y-assembly mixer for 1/16" outer diameter tubing, 0.60" thru hole and finger tighten. Further tighten this joint with the extender tool for standard head nuts. CRITICAL STEP Over tightening the nut can lead to PFA tubing damage and cracking of the nut. Furthermore, a Y-mixer is used in this example to stop solid formation upon mixing of $\mathbf{1}$ and $\mathbf{2}$.

3| Using Part 3 "Pressurization of the Zaiput variable back pressure regulator", charge a back pressure regulator to 200 psi and attach it to the other end of the reactor coil. Finger tighten and then further tighten with the extender tool for standard head nuts and then pliers (Fig. 12). CRITICAL STEP Over tightening the nut can lead to PFA tubing damage and cracking of the nut.

4| Place the reactor coil into an oil bath and secure the exit and entry of the reactor coil by use of binder clips (Fig. 12F). Ensure that the silicone oil covers the reactor to ensure even heating. CRITICAL STEP Make sure that the binder clips are not pressing upon the reactor tubing, this can lead to a clog.

5| Secure the first PEEK Y-assembly mixer by holding it in place with a clamp (Fig. 12F).

6| Secure the back pressure regulator with a clamp (Figs. 12 C and F). CRITICAL STEP Ensure the exit of the reactor is attached to inlet of the back pressure regulator in the orientation as shown in Fig. 12F.

7| Using Part 1 “Assembling of a reactor coil", assemble a $10 \mathrm{~cm}$ long reactor from 0.02 " inner diameter DuPont ${ }^{\circledR}$ tubing with super flangeless nuts ${ }^{\mathrm{TM}}$, and ferrule sets for $1 / 16$ " outer diameter tubing on both ends.

$\mathbf{8}$ Insert one end of the $10 \mathrm{~cm}$ reactor into the exit of the back pressure regulator and finger tighten. Further tighten this joint with the extender tool for standard head nuts and then pliers (Fig. 12E). CRITICAL STEP Over tightening the nut can lead to PFA tubing damage and cracking of the nut.

9| Insert the other end of the $10 \mathrm{~cm}$ reactor into a second PEEK Y-assembly mixer for 1/16" outer diameter tubing, 0.60" thru hole and finger tighten (Fig. 12E). Further tighten this joint with the extender tool for standard head nuts. CRITICAL STEP Over tightening the nut can lead to PFA tubing damage and cracking of the nut.

10| Using Part 1 “Assembling of a reactor coil", assemble a $20 \mathrm{~cm}$ long reactor from 0.02 " inner diameter DuPont ${ }^{\circledR}$ tubing with super flangeless nuts ${ }^{\mathrm{TM}}$, and ferrule sets for $1 / 16$ " outer diameter tubing.

11 Insert one end of the $20 \mathrm{~cm}$ reactor into the second PEEK Y-assembly mixer and finger tighten (Fig. 12E). Further tighten this joint with the extender tool for standard head nuts. CRITICAL STEP Over tightening the nut can lead to PFA tubing damage and cracking of the nut.

12 Insert the other end of the $20 \mathrm{~cm}$ reactor into a $25 \mathrm{~mL}$ glass beaker; this will serve as the collection vial during system equilibration. 


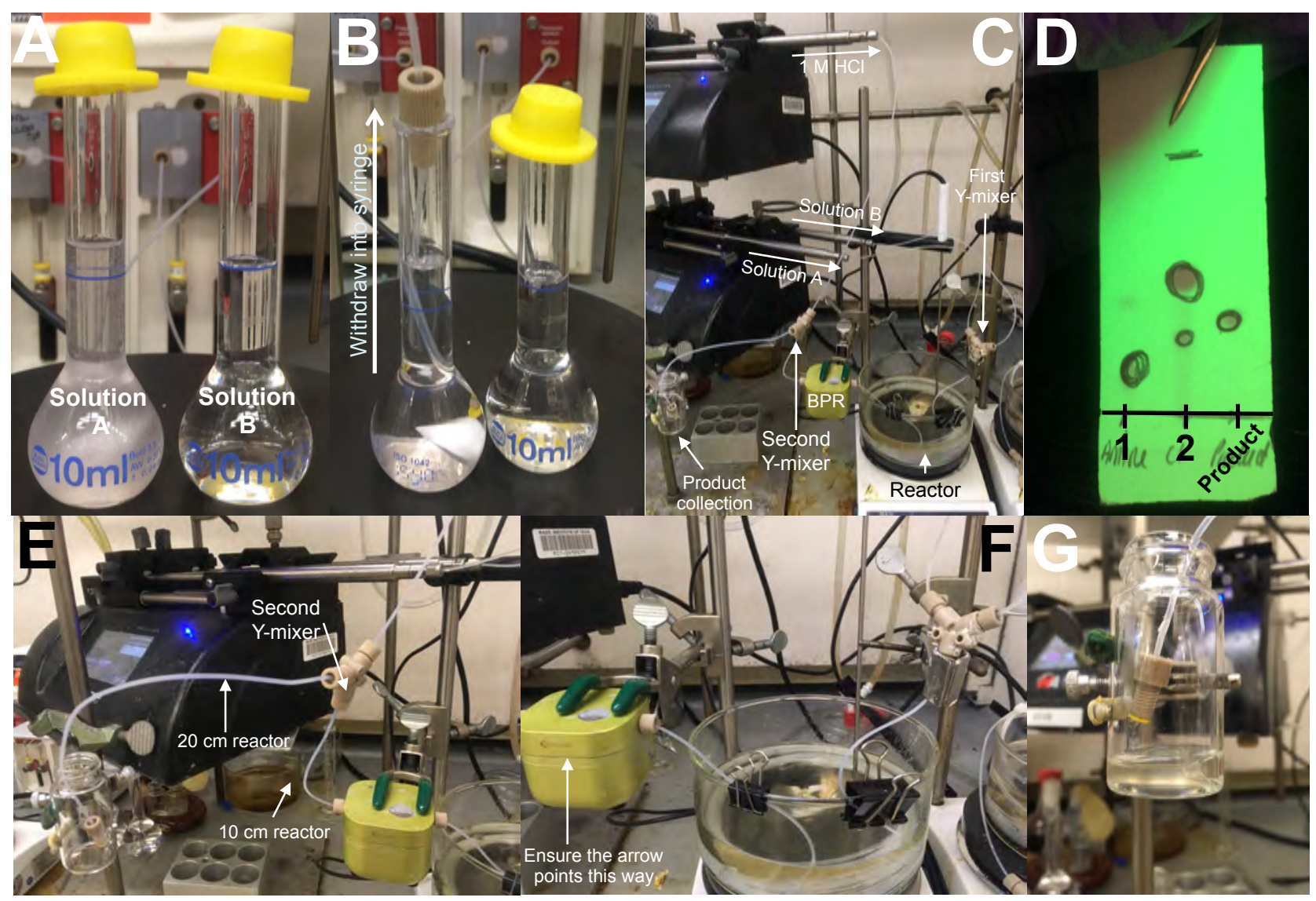

Figure 12| Continuous-flow reactor set up for the synthesis of sulfonamide 3. (A) Solutions A and B before mixing. (B) Solutions A and B after mixing showing complete sample homogeneity. (C) The reactor set up highlighting the three stainless steel syringes, two Y-mixers, the reactor, back pressure regulator, and the product collection flask. (D) TLC of dibenzylamine 1 and 4 chlorobenzenesulfonyl chloride 2 against the product * in a 1:10 ethyl acetate: hexane solution. (E) A photograph of the quenching stage of the reaction. (F) The reactor is placed into the oil bath and clipped into place using binder clips. To note is the orientation of the exit of the reactor into the back pressure regulator. (G) The product collection flask showing the crude reaction mixture is a light brown colour.

\section{(ii) Preparing chemical solutions and loading into stainless steel syringes TIMING 20 min}

1) Charge a weighing boat with 4-chlorobenzenesulfonyl chloride 2 (1.00 g, 4.78 mmol, 1.00 equiv). Transfer the 4chlorobenzenesulfonyl chloride to a $10 \mathrm{~mL}$ volumetric flask, add DMSO (50 $\mu \mathrm{L})$, and then stopper the flask. This is flask A.

2| Charge a $10 \mathrm{~mL}$ volumetric flask with dibenzylamine $\mathbf{1}(1.083 \mathrm{~g}, 5.26 \mathrm{mmol}, 1.10$ equiv) and triethylamine $(1344 \mu \mathrm{L}$, $9.57 \mathrm{mmol}, 2.00$ equiv) and stopper the flask. This is flask $\mathbf{B}$.

3| Add anhydrous DCM to both flasks using a disposable $10 \mathrm{~mL}$ plastic syringe and a hypodermic needle under typical air free conditions to create $\sim 9 \mathrm{~mL}$ final volume solutions (Fig. 12A).

4| Add 1/2" PTFE stir bars to both solutions A and B and stir at $300 \mathrm{rpm}$ for $10 \mathrm{~min}$ at RT. This will completely dissolve 2 and ensure mixture homogeneity (Fig. 12B). Adjust the volumes of both solutions to $10 \mathrm{~mL}$ by adding anhydrous DCM using a disposable $10 \mathrm{~mL}$ plastic syringe and a hypodermic needle under typical air free conditions. CRITICAL STEP Dissolving solids changes the volume of solutions. Adding only $9 \mathrm{~mL}$ of DCM before dissolution ensures any volume change will not exceed $10 \mathrm{~mL}$.

5| Using Part 3 "Assembly of a generic continuous-flow system" withdraw $8 \mathrm{~mL}$ of solution A into a stainless steel syringe. Load, and secure, the stainless steel syringe into a Harvard syringe pump. Attach the tubing from exit of the 
stainless steel syringe to the first PEEK Y-assembly mixer at the entry of the reactor and finger tighten (Fig. 12C). Further tighten this joint with the extender tool for standard head nuts. CRITICAL STEP Over tightening the nut can lead to PFA tubing damage and cracking of the nut.

6| Repeat step 5 with the solution from flask $\mathbf{B}$, and insert the stainless steel syringe into the same Harvard syringe pump.

7| Using Part 3 "Assembly of a generic continuous-flow system" withdraw $8 \mathrm{~mL}$ of a $1 \mathrm{M} \mathrm{HCl}$ solution into a stainless steel syringe. Insert this stainless steel syringe into a different Harvard syringe pump. Secure the stainless steel syringe and attach the tubing from the exit of the stainless steel syringe into the second PEEK Y-assembly mixer at the end of the continuous-flow system (Fig. 12E). Further tighten this joint with the extender tool for standard head nuts. CRITICAL STEP Over tightening the nut can lead to PFA tubing damage and cracking of the nut.

8| Before starting the experiment, ensure that all connections are secure and that the stainless steel syringes are properly secured into the Harvard syringe pumps.

\section{(iii) Performing the experiment TIMING $40 \mathrm{~min}$}

1) Set the temperature of the oil bath to $80{ }^{\circ} \mathrm{C}$ and the stir rate to $400 \mathrm{rpm}$. Wait until the temperature of the oil bath is stable for at least ten min.

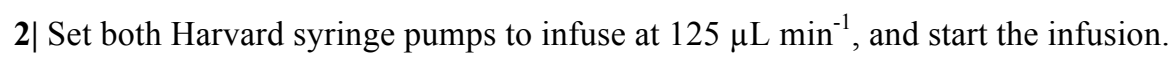

3| Allow the system to equilibrate for at least $35 \mathrm{~min}$.

4| When ready for collection, first, set a timer for $10.3 \mathrm{~min}$ (allows for $1.00 \mathrm{~mL}(0.4784 \mathrm{mmol})$ of the rate limiting reagent to pass through the system). Second, change the equilibration beaker for a new $25 \mathrm{ml}$ glass beaker and immediately start the timer.

5| After 10.3 min immediately remove the collection beaker and replace with the equilibration beaker used previously. The fluid collected contains a theoretical maximum yield of $0.4784 \mathrm{mmol}$.

6| Transfer the collection fluid to a $125 \mathrm{~mL}$ separatory funnel. Rinse the collection vial with DCM (5 x $5 \mathrm{~mL})$ and transfer the washings to the separatory funnel.

7| Add $25 \mathrm{~mL}$ of $1 \mathrm{M} \mathrm{HCl}$ into the separatory funnel; stopper the separatory funnel and then shake. This is referred to as a typical organic liquid-liquid separation. After shaking, allow the layers to separate and collect the lower organic layer, discard the aqueous layer to waste as this contains residual dibenzylamine.

8| Transfer the organic layer back into the separatory funnel and add $25 \mathrm{~mL}$ of $1 \mathrm{M} \mathrm{NaCl}$. Perform a liquid-liquid extraction. Collect the lower layer (organic), and discard the aqueous layer to waste.

9| Transfer the organic layer back into the separatory funnel, and add $25 \mathrm{~mL}$ of deionized $\mathrm{H}_{2} \mathrm{O}$. Perform a liquid-liquid extraction. Collect the lower layer (organic) and discard the aqueous layer to waste.

10| Add $\sim 700 \mathrm{mg}$ of $\mathrm{MgSO}_{4}$ to the organic layer and swirl for $2 \mathrm{~min}$ to dry the solution. The solution will achieve a snow globe effect once dry. If $700 \mathrm{mg}$ of $\mathrm{MgSO}_{4}$ does not achieve this effect, add small portions until achieved.

11| Filter the solution into a $250 \mathrm{~mL}$ round bottom flask using a glass powered funnel and qualitative filter paper.

12| Carefully remove the organic solvent under reduced pressure using a rotatory evaporator; a white power will result.

13| Take a small quantity of this solid $(\sim 1 \mathrm{mg})$ and add it to $5 \mathrm{~mL}$ of ethyl acetate. Perform TLC analysis of the product $\left(\mathrm{R}_{\mathrm{f}}=0.368\right)$ using 1:10 ethyl acetate: hexanes against both 4-chlorobenzenesulfonoyl chloride $2\left(\mathrm{R}_{\mathrm{f}}=0.500\right)$ and dibenzylamine $1\left(\mathrm{R}_{\mathrm{f}}=0.205\right)$. The TLC should indicate a single product under UV radiation (Fig. 12D).

14| Perform column chromatography ( $25 \mathrm{~g}$ silica column, height $=7.0 \mathrm{~cm}$, diameter $=3.0 \mathrm{~cm})$ with an $8 \%$ solution of ethyl acetate in hexanes. The product will elute at 6-9 column volumes. 
15| Combine the fractions containing the desired product and remove the solvent under reduced pressure using a rotary evaporator. Dissolve the resulting solid into a small amount of DCM $(\sim 5 \mathrm{~mL})$, and transfer to a pre-weighed $25 \mathrm{~g}$ vial.

16| Remove the solvent under reduced pressure using a rotatory evaporator until dry. Further dry the product under vacuum at $40{ }^{\circ} \mathrm{C}$ for $2 \mathrm{~h}$. Weight the $25 \mathrm{~g}$ vial to obtain the mass of the product. The theoretical yield for this transformation is $177.5 \mathrm{mg}$.

\section{ANTICIPATED RESULTS}<smiles>O=S(=O)(c1ccc(Cl)cc1)N(Cc1ccccc1)Cc1ccccc1</smiles>

Isolated as a white solid ( $\mathrm{Rf}=0.368 \mathrm{in} \mathrm{1:10} \mathrm{EtOAc:} \mathrm{hexanes)} 133.1 \mathrm{mg}$, yield: $75 \% .{ }^{1} \mathrm{H} \mathrm{NMR}\left(500 \mathrm{MHz}, \mathrm{CDCl}_{3}, 20{ }^{\circ} \mathrm{C}\right)$ : $\delta_{\mathrm{H}}=7.75\left(\mathrm{dt},{ }^{3} J(\mathrm{H}, \mathrm{H})=8.66 \mathrm{~Hz},{ }^{4} J(\mathrm{H}, \mathrm{H})=1.95 \mathrm{~Hz}, 2 \mathrm{H}\right.$; Aryl- $\left.\underline{\mathrm{H}}\right), 7.47\left(\mathrm{dt},{ }^{3} J(\mathrm{H}, \mathrm{H})=8.70 \mathrm{~Hz},{ }^{4} J(\mathrm{H}, \mathrm{H})=1.98 \mathrm{~Hz}, 2 \mathrm{H}\right.$; Aryl$\underline{\mathrm{H}}$ ), 7.26-7.23 (m, 6H; Aryl- $\underline{\mathrm{H}}), 7.10-7.05$ (m, 4H; Aryl-H), 4.34 (s, 4H; $\left.\left.\underline{\mathrm{CH}}_{2}\right) ;{ }^{13} \mathrm{C} \mathrm{NMR} \mathrm{(150} \mathrm{MHz}^{\mathrm{CDCl}}{ }_{3}, 20{ }^{\circ} \mathrm{C}\right)$ : $\delta_{\mathrm{C}}=; 139.4,139.0,135.4,129.4,128.7,128.6,128.0,50.7$; HRMS (70 eV): m/z calcd. for $\mathrm{C}_{20} \mathrm{H}_{18} \mathrm{ClNO}_{2} \mathrm{~S}\left[\mathrm{H}^{+}\right.$adduct]; 372.0820; found 372.0834 .

\section{TIMING}

Procedure i| Assembly of a reactor coil: $\sim 10 \mathrm{~min}$

Procedure ii| Assembly of a stainless steel syringe: $\sim 10 \mathrm{~min}$

Procedure iii| Assembly of a basic continuous-flow system: $\sim 30 \mathrm{~min}$

Procedure iv| Assembly of a static mixer: $\sim 10 \mathrm{~min}$

Procedure v| Assembly of a packed bed reactor: $\sim 30 \mathrm{~min}$

Procedure vi| Use of an in-line liquid-liquid separator: $\sim 30 \mathrm{~min}$

Procedure vii| Assembly of a drying unit: $\sim 24 \mathrm{~h}$

Example Reaction| $90 \mathrm{~min}$

\section{TROUBLESHOOTING}

\begin{tabular}{|c|c|c|c|}
\hline Step & Problem & Possible reason & Solution \\
\hline \multirow[t]{2}{*}{ Procedure i, Step 7} & \multirow{2}{*}{$\begin{array}{l}\text { The PFA tubing } \\
\text { disconnected from the } \\
\text { super flangeless nut }{ }^{\mathrm{TM}} \\
\text { after tightening. }\end{array}$} & $\begin{array}{l}\text { The components were not } \\
\text { correctly oriented on the } \\
\text { PFA before tightening. }\end{array}$ & $\begin{array}{l}\text { Attach a new ferrule set in the order, and } \\
\text { orientation, as shown in Figure } 3 \mathrm{~A} \text { and } \mathrm{B} \text {. } \\
\text { Do not reuse ferrule set. }\end{array}$ \\
\hline & & $\begin{array}{l}\text { The ferrule was not around } \\
\text { the PFA tubing when the } \\
\text { super flangeless nut }{ }^{\mathrm{TM}} \text { was } \\
\text { tightened into the union, or } \\
\text { the super flangeless nut } \\
\text { was not tightened enough. }\end{array}$ & $\begin{array}{l}\text { When tightening the super flangeless nut }{ }^{\mathrm{TM}} \\
\text { apply pressure to the PFA tubing as shown } \\
\text { in Figure } 3 \mathrm{C} \text { to ensure the ferrule is set } \\
\text { around the PFA tubing. Do not reuse } \\
\text { ferrule. }\end{array}$ \\
\hline Procedure & $\begin{array}{l}\text { The PFA tubing } \\
\text { disconnected from the } \\
\text { syringe connector. }\end{array}$ & $\begin{array}{l}\text { The ferrule set was not } \\
\text { around the PFA tubing } \\
\text { when tightened. }\end{array}$ & $\begin{array}{l}\text { When tightening the metal nut into the } \\
\text { syringe connector, apply pressure to the } \\
\text { PFA tubing to ensure the ferrule is set } \\
\text { around the PFA tubing. }\end{array}$ \\
\hline \multirow[t]{2}{*}{ Procedure ii, Step 8} & \multirow{2}{*}{$\begin{array}{l}\text { The PFA tubing } \\
\text { disconnected from the } \\
\text { super flangeless nut }{ }^{\mathrm{TM}} \\
\text { after tightening. }\end{array}$} & $\begin{array}{l}\text { The components were not } \\
\text { correctly oriented on the } \\
\text { PFA before tightening. }\end{array}$ & $\begin{array}{l}\text { Attach a new ferrule set in the order, and } \\
\text { orientation, as shown in Figure } 3 \mathrm{~A} \text { and } \mathrm{B} \text {. } \\
\text { Do not reuse ferrule set. }\end{array}$ \\
\hline & & The ferrule was not around & When tightening the super flangeless nut ${ }^{\mathrm{TM}}$ \\
\hline
\end{tabular}




\begin{tabular}{|c|c|c|c|}
\hline & & $\begin{array}{l}\text { the PFA tubing when the } \\
\text { super flangeless nut }{ }^{\mathrm{TM}} \text { was } \\
\text { tightened into the union, or } \\
\text { the super flangeless nut } \\
\text { was not tightened enough. }\end{array}$ & $\begin{array}{l}\text { apply pressure to the PFA tubing as shown } \\
\text { in Figure } 3 \mathrm{C} \text { to ensure the ferrule is set } \\
\text { around the PFA tubing. Do not reuse } \\
\text { ferrule. }\end{array}$ \\
\hline & & $\begin{array}{l}\text { A failure of the Swagelok to } \\
\text { PFA connection is common. } \\
\text { Mechanical stress leads to } \\
\text { the stainless steel biting into } \\
\text { the PFA tubing. }\end{array}$ & $\begin{array}{l}\text { This region of the tubing should be } \\
\text { inspected before every use. It should be } \\
\text { replaced if wear is observed. }\end{array}$ \\
\hline & $\begin{array}{l}\text { The syringe plunger } \\
\text { has become sticky and } \\
\text { hard to operate when } \\
\text { being filled with fluid. }\end{array}$ & $\begin{array}{l}\text { The grease has been } \\
\text { removed from the O-rings. }\end{array}$ & $\begin{array}{l}\text { Ensure regulator maintenance is conducted. } \\
\text { Grease the O-rings of the syringe plunger } \\
\text { with Krytox grease during maintenance. }\end{array}$ \\
\hline $\begin{array}{l}\text { Procedure iiia, Step } \\
8\end{array}$ & $\begin{array}{l}\text { The gas delivery tube } \\
\text { detaches from the } \\
\text { compressed air tank } \\
\text { valve at high pressures. }\end{array}$ & $\begin{array}{l}\text { The gas delivery tube is not } \\
\text { secure. }\end{array}$ & $\begin{array}{l}\text { Tighten the metal nut at the end of the gas } \\
\text { delivery tube to ensure a firm fit between } \\
\text { the back pressure regulator and the gas } \\
\text { delivery tubing. }\end{array}$ \\
\hline \multirow[t]{2}{*}{$\begin{array}{l}\text { Procedure iiia, Step } \\
9\end{array}$} & \multirow{2}{*}{$\begin{array}{l}\text { The back pressure } \\
\text { regulator does not } \\
\text { allow fluid though } \\
\text { when not connected to } \\
\text { a flow system (i.e. } \\
\text { stand alone) }\end{array}$} & The device is broken. & $\begin{array}{l}\begin{array}{l}\text { Contact Zaiput Flow Technologies for } \\
\text { advice. }\end{array} \\
\text { ld }\end{array}$ \\
\hline & & $\begin{array}{l}\text { The fluid from the } \\
\text { continuous-flow system is } \\
\text { entering the wrong side of } \\
\text { the separator. }\end{array}$ & $\begin{array}{l}\text { Switch the entry and exit tubes of the back } \\
\text { pressure regulator. The engraved arrow on } \\
\text { the back pressure regulator shows the } \\
\text { direction of fluid flow. }\end{array}$ \\
\hline \multirow[t]{2}{*}{$\begin{array}{l}\text { Procedure iiib, Step } \\
2\end{array}$} & \multirow{2}{*}{$\begin{array}{l}\text { The PFA tubing } \\
\text { disconnected from the } \\
\text { super flangeless nut }{ }^{\mathrm{TM}} \\
\text { after tightening. }\end{array}$} & $\begin{array}{l}\text { The components were not } \\
\text { correctly oriented on the } \\
\text { PFA before tightening. }\end{array}$ & $\begin{array}{l}\text { Attach a new ferrule set in the order, and } \\
\text { orientation, as shown in Figure } 3 \mathrm{~A} \text { and } \mathrm{B} \text {. } \\
\text { Do not reuse ferrule set. }\end{array}$ \\
\hline & & $\begin{array}{l}\text { The ferrule was not around } \\
\text { the PFA tubing when the } \\
\text { super flangeless nut } \\
\text { tightened into the union, or } \\
\text { the super flangeless nut } \\
\text { was not tightened enough. }\end{array}$ & $\begin{array}{l}\text { When tightening the super flangeless nut } \\
\text { apply pressure to the PFA tubing as shown } \\
\text { in Figure } 3 \mathrm{C} \text { to ensure the ferrule is set } \\
\text { around the PFA tubing. Do not reuse } \\
\text { ferrule. }\end{array}$ \\
\hline $\begin{array}{l}\text { Procedure iiib, Step } \\
7\end{array}$ & $\begin{array}{l}\text { The use of air or } \\
\text { moisture sensitive } \\
\text { reagents is required; } \\
\text { How do I load them } \\
\text { into the stainless steel } \\
\text { syringes under } \\
\text { appropriate conditions? }\end{array}$ & $\begin{array}{l}\text { Stainless steel syringes } \\
\text { require the reagents to be } \\
\text { drawn up by the user, so } \\
\text { this has to be carried out } \\
\text { under air-free conditions. }\end{array}$ & $\begin{array}{l}\text { (a) Prepare the solutions to be flowed } \\
\text { through the continuous-flow system as you } \\
\text { would for typical syntheses, i.e. in a round } \\
\text { bottom flask or screw top vial. Next, screw } \\
\text { a quick-stop luer in-line check valve (IDEX } \\
\text { Health \& Science, \#P-655) to the super } \\
\text { flangeless nut }{ }^{\mathrm{TM}} \text { of the stainless steel } \\
\text { syringe and join a suitable needle. Using } \\
\text { this needle, the solutions can be loaded into } \\
\text { the syringes using the same method as you } \\
\text { would use to remove anhydrous solvent } \\
\text { from a solvent bottle (standard air sensitive } \\
\text { syringe techniques). } \\
\text { (b) Syriss Asia pumps remove the need to } \\
\text { transfer solutions from schlenk flasks into } \\
\text { syringes. Attaching a quick-stop luer in-line } \\
\text { check valve and needle to the pump allows } \\
\text { direct infusion into the continuous-flow } \\
\text { system. However, these pumps cost } \\
\sim \$ 20,000 \text { USD. } \\
\text { (c) To note is that if reagents are highly air } \\
\text { sensitive, then PFA tubing allows slow } \\
\text { permeation of air and moister. This will } \\
\text { lead to poor yields. Use stainless steel } \\
\text { tubing for the reactor coil. }\end{array}$ \\
\hline $\begin{array}{l}\text { Procedure iiib, Step } \\
8\end{array}$ & $\begin{array}{l}\text { Reactor coil does not } \\
\text { submerge in the oil } \\
\text { bath. }\end{array}$ & $\begin{array}{l}\text { Orientation or buoyancy of } \\
\text { the reactor is wrong. }\end{array}$ & $\begin{array}{l}\text { Clip the entrance and exit of the reactor coil } \\
\text { to the oil bath. Ensure the orientation of the } \\
\text { reactor coil leaves it fully submerged in oil/ }\end{array}$ \\
\hline
\end{tabular}




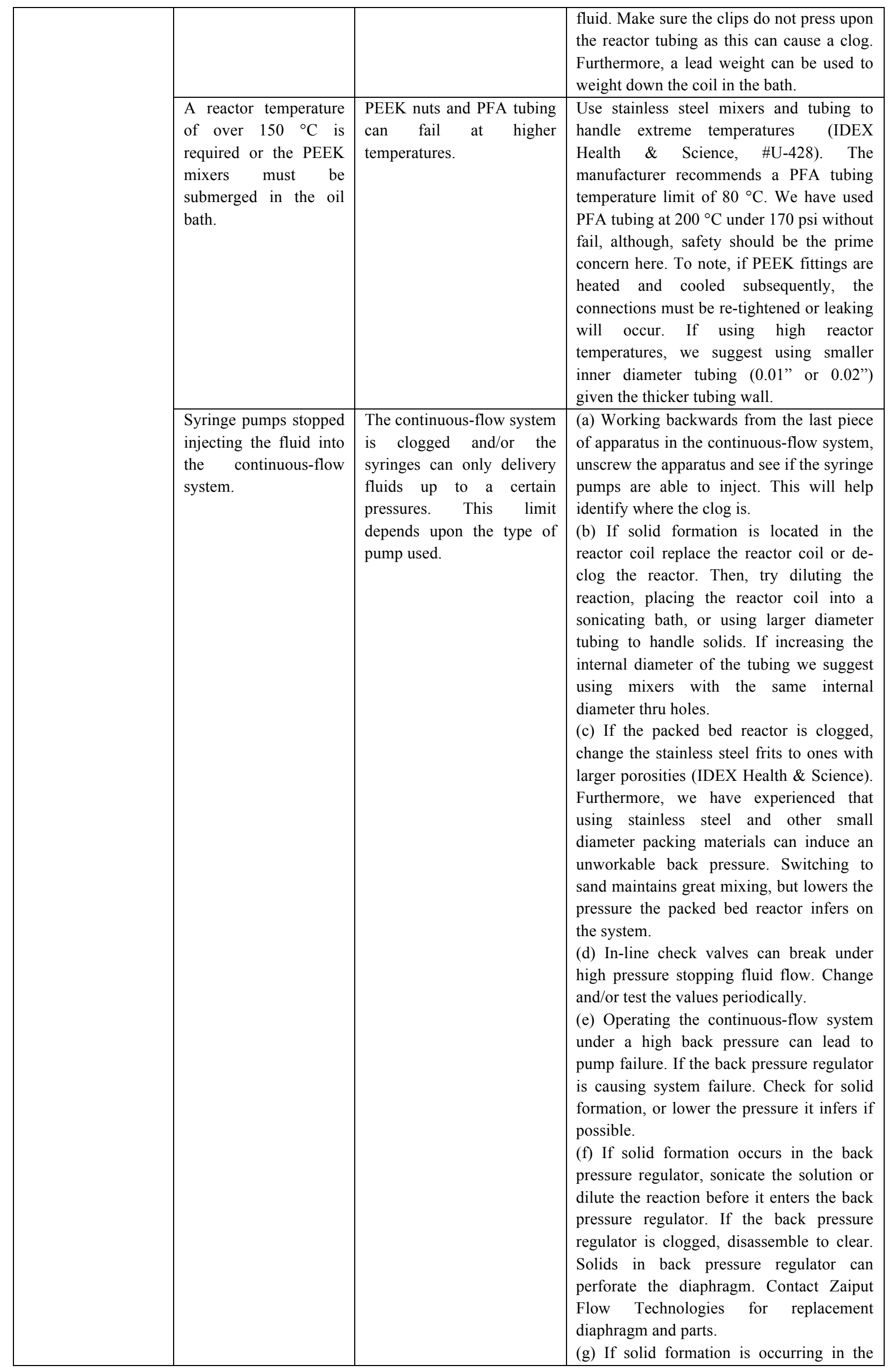




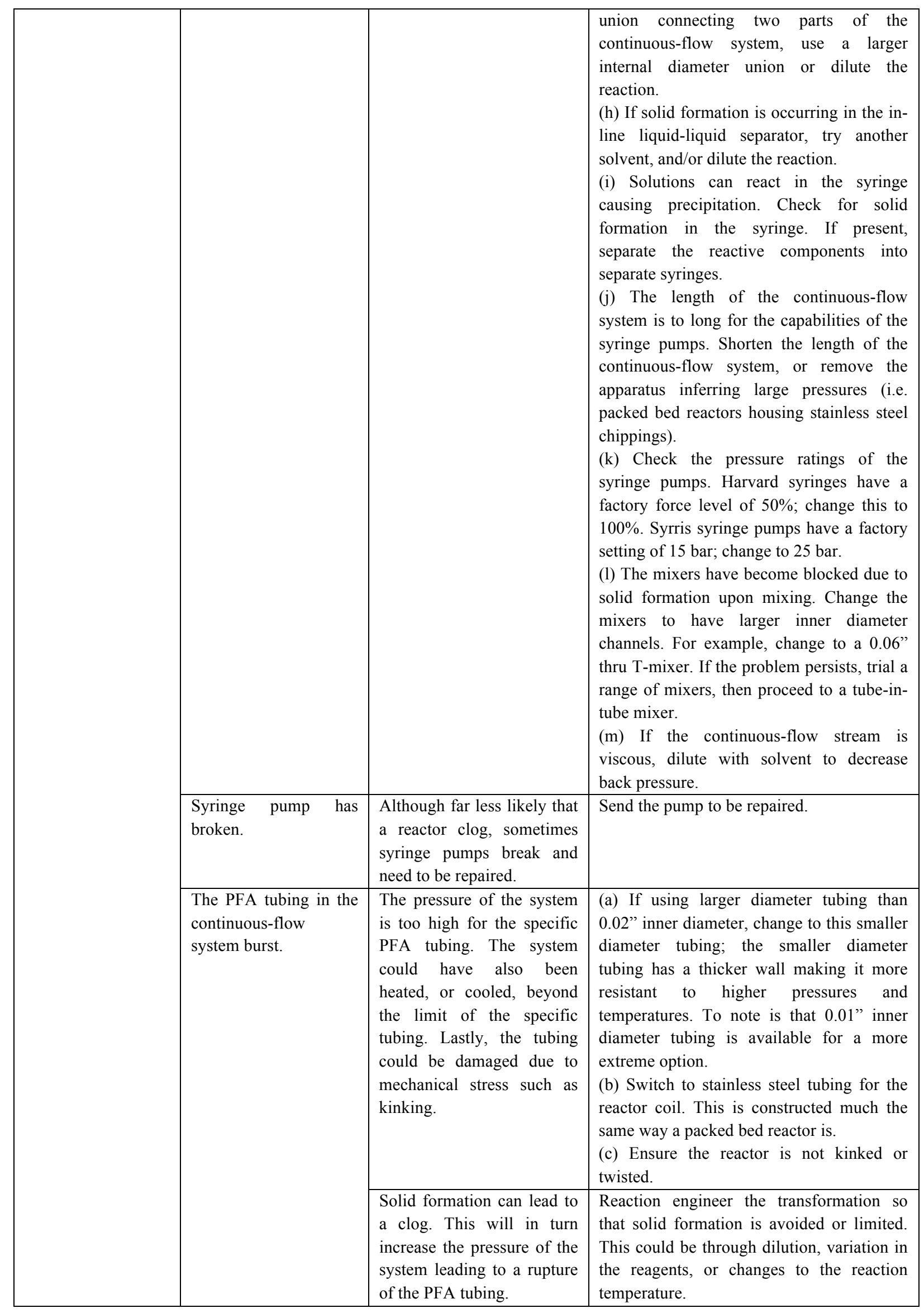




\begin{tabular}{|c|c|c|c|}
\hline & & $\begin{array}{l}\text { The reaction releases a large } \\
\text { volume of gas that } \\
\text { dramatically increases the } \\
\text { system pressure. }\end{array}$ & $\begin{array}{l}\text { (a) Dilute the reaction. } \\
\text { (b) Lower the back pressure regulator to } \\
\text { decrease the total system pressure. } \\
\text { (c) If gas release is due to reagent } \\
\text { degradation, contemplate different reaction } \\
\text { conditions such as a lower reaction } \\
\text { temperature. }\end{array}$ \\
\hline & \multirow[t]{2}{*}{$\begin{array}{l}\text { Lower yields are } \\
\text { observed when the } \\
\text { continuous-flow } \\
\text { system gets longer or } \\
\text { more complex. }\end{array}$} & $\begin{array}{l}\text { In general, a larger system } \\
\text { has higher pressures, thus, if } \\
\text { operating at low flow rates } \\
(\sim 10 \mu 1 / \mathrm{min}) \text { the syringe } \\
\text { driver can slip, lowering the } \\
\text { amount of reagent added to } \\
\text { the continuous-flow system. } \\
\text { This will reduce the yield. }\end{array}$ & $\begin{array}{l}\text { Use higher flow rates to avoid the syringe } \\
\text { slipping at lower flow rates. An increase in } \\
\text { the length of the reactor coils will have to } \\
\text { occur for the residence time to stay the } \\
\text { same. Furthermore, ensure the syringe size } \\
\text { is correctly inputted into the syringe pump. }\end{array}$ \\
\hline & & $\begin{array}{l}\text { Long pieces of PFA tubing } \\
\text { between back pressure } \\
\text { regulators, packed bed } \\
\text { reactors, T-mixers and } \\
\text { drying units can create } \\
\text { complex pressure gradients. } \\
\text { Instead of flowing in one } \\
\text { direction it can recycle } \\
\text { around. This can lead to } \\
\text { lower yields or over } \\
\text { reactivity. }\end{array}$ & $\begin{array}{l}\text { (a) Reduce the dead volume in the system. } \\
\text { Have the shortest amount of PFA tubing } \\
\text { possible between apparatus. } \\
\text { (b) If adding several solvents at different T- } \\
\text { mixers, combine all these solvents together } \\
\text { into one stream for mixing with the primary } \\
\text { continuous-flow stream. This means that } \\
\text { instead of several T-mixers, there is only } \\
\text { one, reducing the possibility for complex } \\
\text { pressure gradients. }\end{array}$ \\
\hline Procedure iv, Step 3 & $\begin{array}{lrr}\text { Using } & \text { three } & \text { static } \\
\text { mixers } & \text { does } & \text { not } \\
\text { provide } & & \text { enough } \\
\text { mixing. } & & \end{array}$ & $\begin{array}{l}\text { Static mixers only provide a } \\
\text { certain level of mixing. }\end{array}$ & $\begin{array}{l}\text { Switch to a packed bed reactor housing } \\
\text { sand, stainless steel chippings or glass } \\
\text { beads. This will increase the amount of } \\
\text { micromixing in the system. As mentioned } \\
\text { previously, be careful of the back pressure } \\
\text { this infers on the system. }\end{array}$ \\
\hline $\begin{array}{l}\text { Procedure v, Step } \\
10\end{array}$ & $\begin{array}{l}\text { The part labeled } 0 \text { in } \\
\text { Figure } 8 \mathrm{~A} \text { snaps when } \\
\text { the nut is tightened. }\end{array}$ & $\begin{array}{l}\text { This is the weakest point of } \\
\text { the packed bed reactor. } \\
\text { Over tightening will cause it } \\
\text { to bend and snap. }\end{array}$ & $\begin{array}{l}\text { Be careful when tightening this joint. } \\
\text { Ensure the wrench is at } 90^{\circ} \text { to the packed } \\
\text { bed reactor when tightening. Proceed } \\
\text { carefully. }\end{array}$ \\
\hline $\begin{array}{l}\text { Procedure v, Step } \\
18\end{array}$ & $\begin{array}{l}\text { When tightening the } \\
\text { nut between part } 2 \text { and } \\
\text { part } 1 \text { in Figure } 8 \mathrm{~A} \text {, a } \\
\text { crunching noise is } \\
\text { heard. }\end{array}$ & $\begin{array}{l}\text { There is sand present in } \\
\text { joint. }\end{array}$ & $\begin{array}{l}\text { While covering the entrance to the packed } \\
\text { bed reactor, tap the reactor to loosen sand } \\
\text { or other materials. Subject the nut to } \\
\text { compressed air to blow away loose debris. }\end{array}$ \\
\hline \multirow[t]{5}{*}{$\begin{array}{l}\text { Procedure vi, Step } \\
11\end{array}$} & \multirow[t]{5}{*}{$\begin{array}{l}\text { The separator is not } \\
\text { separating the organic } \\
\text { and aqueous layer. }\end{array}$} & $\begin{array}{l}\text { There is too much pressure } \\
\text { on the stream where no } \\
\text { fluid is exiting. }\end{array}$ & $\begin{array}{l}\text { Change the back pressure regulators to } \\
\text { either lower the pressure on the side where } \\
\text { no fluid is exiting, or increase the pressure } \\
\text { on the side where the fluid is exiting. } \\
\text { Through this process there will be ideal } \\
\text { pressures for optimal separation. }\end{array}$ \\
\hline & & $\begin{array}{l}\text { The membrane is fouled or } \\
\text { is compromised with solids. }\end{array}$ & Replace the membrane. \\
\hline & & $\begin{array}{l}\text { The pore size of the } \\
\text { membrane is to small or to } \\
\text { large for the flow rate being } \\
\text { used. }\end{array}$ & $\begin{array}{l}\text { Change to a different diameter pore size } \\
\text { membrane. The specific type is specified in } \\
\text { the instructions. }\end{array}$ \\
\hline & & $\begin{array}{l}\text { The flow rate going through } \\
\text { the separator is too high. }\end{array}$ & $\begin{array}{l}\text { Lower the flow rate or use a higher capacity } \\
\text { separator. }\end{array}$ \\
\hline & & $\begin{array}{l}\text { The organic layer is } \\
\text { miscible with water. }\end{array}$ & $\begin{array}{l}\text { Add a non-miscible organic solvent for the } \\
\text { extraction process. }\end{array}$ \\
\hline
\end{tabular}




\section{Supplemental videos}

Supplemental video 1| Assembly of a reactor coil.

Supplemental video 2| Assembly of a stainless steel syringe.

Supplemental video 3| Pressurization of a variable back pressure regulator.

Supplemental video 4| Assembly of a basic continuous-flow system.

Supplemental video 5| Assembly of a static mixer

Supplemental video 6| Assembly of a packed bed reactor (stainless steel tube cutting and filing).

Supplemental video 7| Assembly of a packed bed reactor (Swagelok fitting and insertion of the metal frit).

Supplemental video 8| Assembly of a packed bed reactor (loading the metal nut and ferrule set onto the PFA tubing and tightening into the Swagelok union).

Supplemental video 9| Assembly of a packed bed reactor (loading the sand into the packed bed reactor).

Note: Supplemental videos 1-9 are available in the online version of the paper.

\section{Author contributions}

$\mathrm{JB}$ and TFJ wrote the paper.

\section{Acknowledgments}

J.B acknowledges Dr. Anne-Cat. Bédard, Dr. Justin Lummiss, Mr. Thomas A. McTeague, Ms Mary Grace Russell and Dr. Robert Hicklin for their discussions during the construction of this manuscript. J.B and T.F.J thank the Defense Advanced Research Project Agency (DARPA).

\section{Competing financial interests}

T.F.J is a cofounder of Snapdragon Chemistry, Inc., and a scientific adviser for Zaiput Flow Technologies, Continuus Pharmaceuticals, Paraza Pharmaceuticals, and Asymchem.

\section{References}

1 Gutmann, B., Cantillo, D. \& Kappe, C. O. Continuous-Flow Technology-A Tool for the Safe Manufacturing of Active Pharmaceutical Ingredients. Angew. Chem. Int. Ed. 54, 6688-6728 (2015).

2 Movsisyan, M. et al. Taming Hazardous Chemistry by Continuous Flow Technology. Chem. Soc. Rev. 45, 4892-4928, (2016).

3 Webb, D. \& Jamison, T. F. Continuous Flow Multi-Step Organic Synthesis. Chem. Sci. 1, 675-680 (2010).

4 Wiles, C. \& Watts, P. Continuous flow reactors: a perspective. Green Chem. 14, 38-54 (2012).

5 Hartman, R. L., McMullen, J. P. \& Jensen, K. F. Deciding Whether To Go with the Flow: Evaluating the Merits of Flow Reactors for Synthesis. Angew. Chem. Int. Ed. 50, $7502-7519$ (2011).

6 Ley, S. V., Fitzpatrick, D. E., Ingham, R. J. \& Myers, R. M. Organic Synthesis: March of the Machines. Angew. Chem. Int. Ed. 54, 3449-3464 (2015).

7 Newman, S. G. \& Jensen, K. F. The Role of Flow in Green Chemistry and Engineering. Green Chem. 15, 1456-1472 (2013).

8 Wiles, C. \& Watts, P. Continuous Process Technology: a Tool for Sustainable Production. Green Chem. 16, 55-62 (2014).

9 Britton, J. \& Raston, C. L. Multi-step Continuous-Flow Synthesis. Chem. Soc. Rev. (2017).

10 Jähnisch, K., Hessel, V., Löwe, H. \& Baerns, M. Chemistry in Microstructured Reactors. Angew. Chem. Int. Ed. 43, 406-446 (2004).

11 Sahoo, H. R., Kralj, J. G. \& Jensen, K. F. Multistep Continuous-Flow Microchemical Synthesis Involving Multiple Reactions and Separations. Angew. Chem. Int. Ed. 119, 5806-5810 (2007).

12 Wörz, O., Jäckel, K. P., Richter, T. \& Wolf, A. Microreactors - A New Efficient Tool for Reactor Development. Chem. Eng. Technol. 24, 138-142 (2001).

13 Straathof, N. J. W., Su, Y., Hessel, V. \& Noel, T. Accelerated Gas-Liquid Visible Light Photoredox Catalysis with Continuous-Flow Photochemical Microreactors. Nat. Protocols 11, 10-21 (2016).

14 Su, Y., Straathof, N. J. W., Hessel, V. \& Noël, T. Photochemical Transformations Accelerated in Continuous-Flow Reactors: Basic Concepts and Applications. Chem. Eur. J. 20, 10562-10589 (2014).

15 Garlets, Z. J., Nguyen, J. D. \& Stephenson, C. R. J. The Development of Visible-Light Photoredox Catalysis in Flow. Isr. J. Chem. 54, 351-360 (2014).

16 Tucker, J. W., Zhang, Y., Jamison, T. F. \& Stephenson, C. R. J. Visible-Light Photoredox Catalysis in Flow. Angew. Chem. Int. Ed. 51, 4144-4147 (2012).

17 Porta, R., Benaglia, M. \& Puglisi, A. Flow Chemistry: Recent Developments in the Synthesis of Pharmaceutical Products. Org. Process. Res. Dev. 20, 2-25 (2016). 
18 Malet-Sanz, L. \& Susanne, F. Continuous Flow Synthesis. A Pharma Perspective. J. Med. Chem. 55, 4062-4098 (2012).

19 Schaber, S. D. et al. Economic Analysis of Integrated Continuous and Batch Pharmaceutical Manufacturing: A Case Study. Ind. Eng. Chem. Re.s 50, 10083-10092 (2011).

20 Lee, S. L. et al. Modernizing Pharmaceutical Manufacturing: from Batch to Continuous Production. J. Pharm. Innov. 10, 191-199 (2015).

21 Roberge, D. M. et al. Microreactor Technology and Continuous Processes in the Fine Chemical and Pharmaceutical Industry: Is the Revolution Underway? Org. Process. Res. Dev. 12, 905-910 (2008).

22 Wegner, J., Ceylan, S. \& Kirschning, A. Flow Chemistry - A Key Enabling Technology for (Multistep) Organic Synthesis. Adv. Synth. Catal. 354, 17-57 (2012).

23 Zhang, J., Gong, C., Zeng, X. \& Xie, J. Continuous flow chemistry: New strategies for preparative inorganic chemistry. Coord. Chem. Rev. 324, 39-53 (2016).

24 Cambié, D., Bottecchia, C., Straathof, N. J. W., Hessel, V. \& Noël, T. Applications of Continuous-Flow Photochemistry in Organic Synthesis, Material Science, and Water Treatment. Chem. Rev. 116, 10276-10341, (2016).

25 Peng, Y. et al. Room Temperature Batch and Continuous Flow Synthesis of Water-Stable Covalent Organic Frameworks (COFs). Chem. Mater. 28, 5095-5101 (2016).

26 Liu, Z. et al. Continuous Flow Synthesis of ZSM-5 Zeolite on the Order of Seconds. PNAS 113, 14267-14271 (2016).

27 Hajba, L. \& Guttman, A. Continuous-flow biochemical reactors: Biocatalysis, Bioconversion, and Bioanalytical Applications Utilizing Immobilized Microfluidic Enzyme Reactors. J. Flow Chem. 6, 8-12 (2016).

28 Planchestainer, M. et al. Continuous Flow Biocatalysis: Production and In-line Purification of Amines by Immobilised Transaminase from Halomonas Elongata. Green Chem. (2017).

29 Tang, X., Allemann, R. K. \& Wirth, T. Optimising Terpene Synthesis with Flow Biocatalysis. Eur. J. Org. Chem. 2017, 414-418 (2017).

30 Britton, J., Raston, C. L. \& Weiss, G. A. Rapid Protein Immobilization for Thin Film Continuous Flow Biocatalysis. Chem. Commun. 52, 10159-10162 (2016).

31 Britton, J. \& Raston, C. L. Rapid High Conversion of High Free Fatty Acid Feedstock into Biodiesel Using Continuous Flow Vortex Fluidics. RSC Adv. 5, 2276-2280 (2015).

32 Britton, J. \& Raston, C. L. Continuous Flow Vortex Fluidic Production of Biodiesel. RSC Adv. 4, 49850-49854, (2014).

33 Choedkiatsakul, I., Ngaosuwan, K., Assabumrungrat, S., Mantegna, S. \& Cravotto, G. Biodiesel Production in a Novel Continuous Flow Microwave Reactor. Renew. Energ. 83, 25-29 (2015).

34 Asadi, M., Hooper, J. F. \& Lupton, D. W. Biodiesel Synthesis using Integrated Acid and Base Catalysis in Continuous Flow. Tetrahedron 72, 3729-3733 (2016).

35 Roberge, D. M., Ducry, L., Bieler, N., Cretton, P. \& Zimmermann, B. Microreactor Technology: A Revolution for the Fine Chemical and Pharmaceutical Industries? Chem. Eng. Technol. 28, 318-323 (2005).

36 Adamo, A. et al. On-demand Continuous-Flow Production of Pharmaceuticals in a Compact, Reconfigurable System. Science 352, 61-67 (2016).

37 Snead, D. R. \& Jamison, T. F. A Three-Minute Synthesis and Purification of Ibuprofen: Pushing the Limits of Continuous-Flow Processing. Angew. Chem. Int. Ed. 54, 983-987 (2015).

38 Snead, D. R. \& Jamison, T. F. End-to-end Continuous Flow Synthesis and Purification of Diphenhydramine Hydrochloride Featuring Atom Economy, In-line Separation, and Flow of Molten Ammonium Salts. Chem. Sci. 4, 2822-2827 (2013).

39 Dai, C., Snead, D. R., Zhang, P. \& Jamison, T. F. Continuous-Flow Synthesis and Purification of Atropine with Sequential In-line Separations of Structurally Similar Impurities. J. Flow Chem. 5, 133-138 (2015).

40 Zhang, P., Russell, M. G. \& Jamison, T. F. Continuous Flow Total Synthesis of Rufinamide. Org. Process. Res. Dev. 18, 1567-1570 (2014).

41 Mascia, S. et al. End-to-End Continuous Manufacturing of Pharmaceuticals: Integrated Synthesis, Purification, and Final Dosage Formation. Angew. Chem. Int. Ed. 52, 12359-12363 (2013).

42 Heider, P. L. et al. Development of a Multi-Step Synthesis and Workup Sequence for an Integrated, Continuous Manufacturing Process of a Pharmaceutical. Org. Process. Res. Dev. 18, 402-409 (2014).

43 McTeague, T. A. \& Jamison, T. F. Photoredox Activation of SF6 for Fluorination. Angew. Chem. Int. Ed. 55, 15072-15075 (2016).

44 Andrade, L. H., Kroutil, W. \& Jamison, T. F. Continuous Flow Synthesis of Chiral Amines in Organic Solvents: Immobilization of E. coli Cells Containing Both $\omega$-Transaminase and PLP. Org. Lett. 16, 6092-6095 (2014).

45 Barnes, J. C. et al. Iterative Exponential Growth of Stereo- and Sequence-Controlled Polymers. Nat. Chem. 7, 810815 (2015).

$46 \mathrm{Wu}$, J. et al. Continuous Flow Synthesis of Ketones from Carbon Dioxide and Organolithium or Grignard Reagents. Angew. Chem. Int. Ed. 53, 8416-8420 (2014).

47 Wu, J., Kozak, J. A., Simeon, F., Hatton, T. A. \& Jamison, T. F. Mechanism-Guided Design of Flow Systems for Multicomponent Reactions: Conversion of CO2 and Olefins to Cyclic Carbonates. Chem. Sci. 5, 1227-1231 (2014). 
48 Zhang, Y., Blackman, M. L., Leduc, A. B. \& Jamison, T. F. Peptide Fragment Coupling Using a Continuous-Flow Photochemical Rearrangement of Nitrones. Angew. Chem. Int. Ed. 52, 4251-4255 (2013).

49 Kleinke, A. S. \& Jamison, T. F. Hydrogen-Free Alkene Reduction in Continuous Flow. Org. Lett. 15, 710-713, (2013).

50 Shen, B. \& Jamison, T. F. Rapid Continuous Synthesis of 5'-Deoxyribonucleosides in Flow via Brønsted Acid Catalyzed Glycosylation. Org. Lett. 14, 3348-3351 (2012).

51 Shen, B., Bedore, M. W., Sniady, A. \& Jamison, T. F. Continuous Flow Photocatalysis Enhanced Using an Aluminum Mirror: Rapid and Selective Synthesis of 2'-deoxy and 2',3'-dideoxynucleosides. Chem. Commun. 48, 7444-7446 (2012).

52 Webb, D. \& Jamison, T. F. Diisobutylaluminum Hydride Reductions Revitalized: A Fast, Robust, and Selective Continuous Flow System for Aldehyde Synthesis. Org. Lett. 14, 568-571 (2012).

53 Leduc, A. B. \& Jamison, T. F. Continuous Flow Oxidation of Alcohols and Aldehydes Utilizing Bleach and Catalytic Tetrabutylammonium Bromide. Org. Process. Res. Dev. 16, 1082-1089 (2012).

54 Palde, P. B. \& Jamison, T. F. Safe and Efficient Tetrazole Synthesis in a Continuous-Flow Microreactor. Angew. Chem. Int. Ed. 50, 3525-3528 (2011).

55 Sniady, A., Bedore, M. W. \& Jamison, T. F. One-Flow, Multistep Synthesis of Nucleosides by Brønsted AcidCatalyzed Glycosylation. Angew. Chem. Int. Ed. 50, 2155-2158 (2011).

56 Zhang, Y., Jamison, T. F., Patel, S. \& Mainolfi, N. Continuous Flow Coupling and Decarboxylation Reactions Promoted by Copper Tubing. Org. Lett. 13, 280-283 (2011).

57 Yoshida, J.-i., Nagaki, A. \& Yamada, T. Flash Chemistry: Fast Chemical Synthesis by Using Microreactors. Chem. Eur. J. 14, 7450-7459 (2008).

58 Yoshida, J.-i., Takahashi, Y. \& Nagaki, A. Flash Chemistry: Flow Chemistry that Cannot be Done in Batch. Chem. Commun. 49, 9896-9904 (2013). 